\title{
El conjunto arqueológico de Saqsaywaman (Cusco): una aproximación a su arquitectura
}

\author{
Ricardo MAR \\ J. Alejandro BeLtrán-CABALLERo \\ Universitat Rovira i Virgili \\ ricardo.mar@urv.cat civitates.network@gmail.com
}

Recibido: 17 de junio de 2013

Aceptado: 14 de noviembre de 2013

\section{RESUMEN}

Saqsaywaman es el conjunto arqueológico más extenso que se ha conservado de la antigua capital imperial del Cusco. A pesar de las grandes excavaciones realizadas en los últimos 70 años, carecemos aún de interpretaciones arquitectónicas y funcionales que reivindiquen su extraordinaria importancia en el contexto de la arquitectura inca. Presentamos en estas páginas el estudio arquitectónico del sector de Muyukmarca como resultado del seminario didáctico sobre «Arqueología de la Arquitectura» realizado en el Cusco entre los años 2010 y 2011. El examen de los restos y las noticias recogidas por los cronistas coloniales permiten afirmar que Saqsaywaman era la gran Casa del Sol de Hanan Qusqu, construida como contrapunto del Coricancha en el diseño unitario de la ciudad decidido por el gran Pachacuti.

Palabras clave: Arquitectura inca, palacios, urbanismo precolonial en América.

\section{The Archaeological Complex of Saqsaywaman (Cusco): An Architectural Approach}

\section{ABSTRACT}

Saqsaywaman is the most extensive archaeological complex of the ancient imperial capital of Cuzco. Despite the excavations carried out in the last 70 years, it lacks even an architectural and functional interpretation that claimed its extraordinary importance in the context of Inca architecture. This paper presents an architectural study of the sector of Muyukmarca as a result of the training seminar on «Archaeology of architecture» held in Cusco between the years 2010 and 2011. The examination of material remains and of information gathered by colonial chroniclers indicates that the most important spaces had religious functions, agreeing on the idea that Saqaywaman was the great Sun House of Hanan Qusqu, built as a counterpoint to Coricancha in the unitary design of the city decided by the great Pachacuti.

Key words: Inka architecture, ancient palaces, precolonial urbanism in America.

Sumario: 1. Introducción: la «Fortaleza» de Saqsaywaman. 2. Las terrazas y los muros perimetrales de la colina. 3. Las grandes unidades constructivas del Sector de Muyukmarca. 4. Huacas y plataformas. 5. Las construcciones de la Plataforma A. 6. La Plataforma B y el Edificio de los Torreones. 7. Las construcciones de la Ladera Sur. 8. Reconstrucción del piso superior del Edificio de los Torreones. 9. Conclusión. 10. Referencias bibliográficas.

«...echaron por tierra aquella gran majestad, indigna de tal estrago, que eternamente hará lástima a los que la miraren con atención de lo que fue» Garcilaso de la Vega (2004 [1609]: 488).

\section{Introducción: la «Fortaleza» de Saqsaywaman}

En el año de 1532 llegaron los primeros españoles al Cusco. La gran capital inca se extendía a lo largo de un valle elevado situado en el corazón de los Andes. En aquel momento era el más importante conjunto urbano de toda Sudamérica, aunque pronto comenzaría su transformación en una ciudad colonial española. Su centro representativo, asentado en la cabecera del valle, estaba formado por los palacios, recintos mo- 


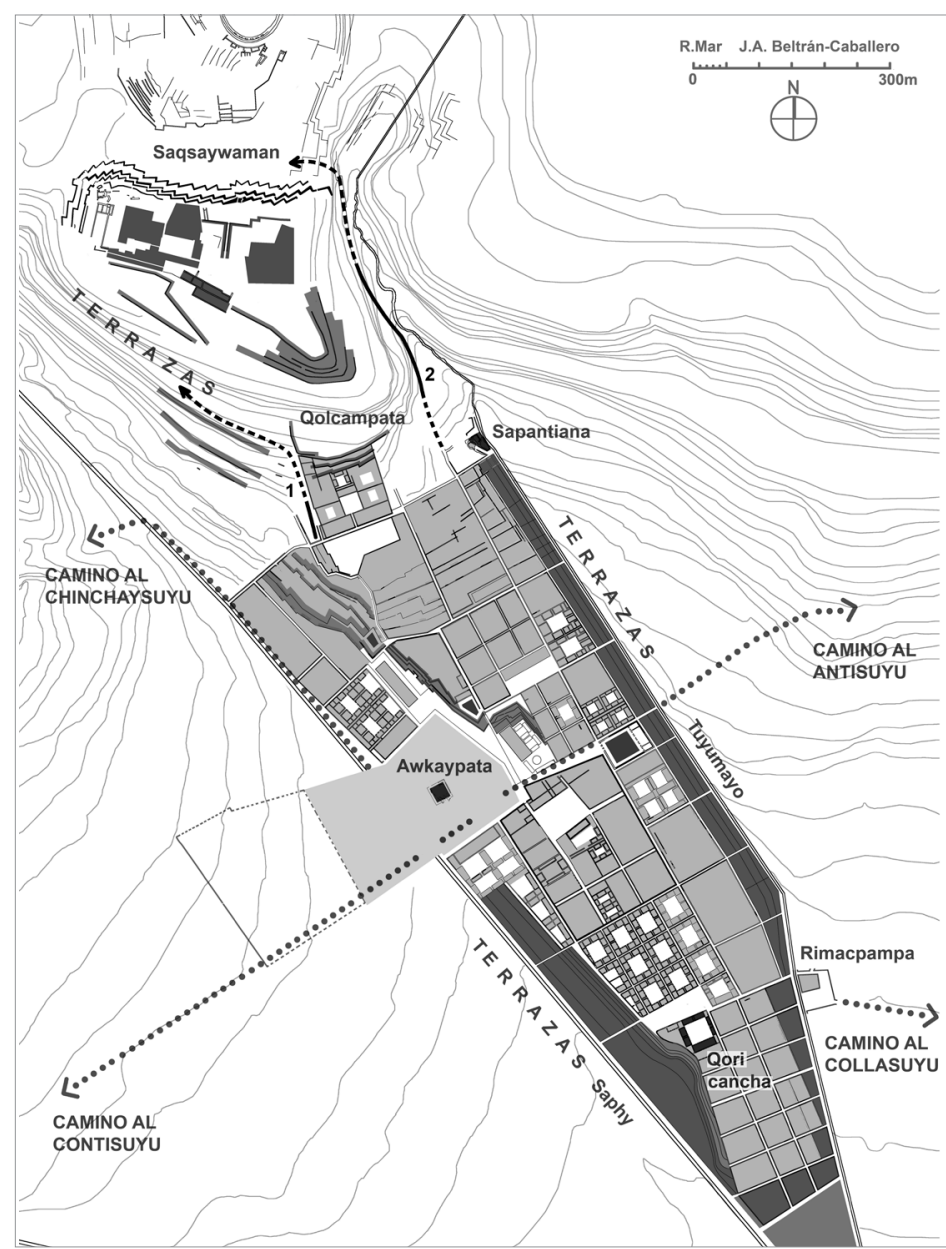

Figura 1: Restitución de la planta general del Cusco inca; «1»y «2»: calles de acceso a Saqsaywaman. (Dibujo: Ricardo Mar y José Alejandro BeltránCaballero).

numentales y templos concentrados entre dos ríos artificialmente canalizados: el Saphi y el Tullumayo (Figura 1). Más allá de sus cauces se situaban los barrios residenciales, asociados con una densa red de terrazas agrícolas, canales de riego y almacenes. Los caminos partían del centro del Cusco y comunicaban, primero, los asentamientos dispersos por el valle, para continuar después por toda la geografía del Tawantinsuyu formando el Qhapaq Nan, o camino del Inca. Dominando todo ello y visible desde cualquier punto del valle, se ubicaba el cerro de Saqsaywaman. Los cronistas recuerdan que estaba ocupado por una gran «fortaleza», con torres y murallas. Debía de ser un conjunto visualmente espectacular si tenemos en cuenta algunas de sus descripciones: «Esta ciudad está asentada en un valle, entre sierras muy ásperas; la mayor parte de ella estaba en una ladera como Burgos, y encima de la ladera una fortaleza de piedra, soberbio y grande edificio, con sus torres y cercas» (Estete 1924 [1535]: 45).

Saqsaywaman fue arrasado en los primeros decenios de la conquista y sus piedras utilizadas como material de construcción. A pesar de ello, sobrevivieron los celebres muros en zigzag que aún siguen impresionando a los visitantes y un importante 
conjunto de restos arqueológicos ${ }^{1}$. Su descubrimiento comenzó en los años 30 del siglo $\mathrm{XX}^{2}$ y ha proseguido hasta nuestros días ${ }^{3}$. En su mayor parte se trata de cimentaciones y obras de subestructura que han perdido los edificios que sostenían. A pesar de ello, aportan una información valiosísima que, complementada con las descripciones literarias de la primera época colonial, nos permite aproximarnos a la reconstrucción de su arquitectura. En este sentido, las descripciones y noticias recogidas por los españoles que llegaron a ver Saqsaywaman antes de su destrucción son una fuente de información imprescindible, aunque por su ambigüedad debe ser tratada con prudencia ${ }^{4}$. Los cronistas reflejan en sus escritos la percepción subjetiva de una realidad cultural muy diferente de la suya, observada desde las contradicciones y los cambios que desgarraban por entonces el Viejo Mundo. Sus esquemas mentales formaban parte de una Castilla que estaba saliendo de la Edad Media y que buscaba su encaje en la construcción de la Europa moderna. Por otra parte, la redacción de las crónicas respondió siempre a motivaciones de tipo ideológico. En algunas ocasiones, fueron redactadas como justificación de la conquista; en otras, formaban parte de la estrategia de los grupos de poder en el virreinato o en la propia España, aunque finalmente, los intereses y circunstancias personales del cronista influyeron siempre en la presentación de los datos. Garcilaso de la Vega escribió desde España, muchos años después de haber abandonado el Perú. Aun así, recordaba que Saqsaywaman formaba un edificio compacto del que sobresalían varios cuerpos compactos en altura. Por ello fueron identificados con los torreones de los castillos medievales.

Hoy en día, muchos investigadores descartan que Saqsaywaman fuese construido para servir de fortaleza (Barreda y Valencia 2007: 132) y proponen su interpretación como centro ceremonial y templo del Sol construido como una parte del mismo Cusco (Silva 2007). Es la idea que recoge Cieza de León (1986 [1553]: 230) cuando afirma que los incas llamaban Casa del Sol a lo que los españoles denominaron fortaleza. Esta controversia refleja las dificultades que en muchas ocasiones plantea la identificación de rasgos específicamente militares en los yacimientos arqueológicos (Arkush y Stanish 2005). La forma de los muros que rodean el cerro parece responder a necesidades militares y protege edificios que, según Sancho de la Hoz (1962 [1534]: 91), sirvieron para almacenar pertrechos militares. Sin embargo, los terraplenes, murallas, fosos y restantes elementos construidos presentan defectos de diseño que habrían impedido su buen funcionamiento defensivo (Topic y Topic 1987 y 1997). Son numerosos los autores que citan este tipo de situaciones en la región andina (Ellefsen 1972; Wilson 1988: 259; Hastorf 1993: 65; Parsons et al. 2000: 167); los ejemplos

1 Para una síntesis del estado del conocimiento sobre el conjunto, véase Anglés Vargas 1990.

2 El volumen Saqsaywaman: estudios fundamentales (2007) recoge los textos del periodo colonial, los antiguos estudios de Squier y de Valcárcel, dos visiones generales del conjunto arqueológico (Barreda y Valencia 2007; Silva 2007) y una serie de artículos sobre las investigaciones arqueológicas realizadas desde 1970 hasta 2007.

3 El documento fundamental es sin duda el Plan Maestro del Parque Arqueológico de Saqsaywaman, redactado para el período 2006-2010 por un amplio equipo técnico del INC bajo la tutela del Dr. David Ugarte, como director regional del Cusco (véase una síntesis del plan en Dammert 2007: 247). El catastro arqueológico incluye 91 zonas arqueológicas.

4 El uso de los textos coloniales como fuente histórica exige la identificación previa de los diferentes niveles que subyacen en el discurso literario; véase, en general, el trabajo de W. Mignolo (2005). 
incluyen murallas que no llegan a cerrar un perímetro, puertas múltiples desprovistas de defensa o asentamientos situados sobre cerros aislados sin abastecimiento de agua. En estos ejemplos, al igual que en Saqsaywaman, se ha descartado la función militar poniendo el acento en su interpretación como fortificaciones simbólicas. Las supuestas estructuras defensivas habrían sido solamente barreras destinadas a jerarquizar el uso ceremonial de los espacios y a fijar las condiciones de accesibilidad de los distintos grupos de la población. Como resultado de este enfoque, importantes construcciones que en algunos casos se remontan al Horizonte Temprano, como Chankillo en el valle de Casma (Topic y Topic 1997: 569), asentamientos extensos como Marcahuamachuco en La Libertad, Inkallacta en Cochabamba o la llamada fortaleza chimú de Paramonga, en el distrito de Barranca, han sido reinterpretadas como centros ceremoniales.

La cuestión está lejos de haber sido resuelta si tenemos en cuenta que muchas de estas construcciones, posiblemente ceremoniales, pudieron tener también un uso defensivo. Así, Arkush y Stanish (2005: 4) reivindican el uso específicamente militar de centros ceremoniales configurados como asentamientos bien defendidos; sería el caso de los pukara, cerros rodeados por uno o varios muros defensivos que constituyen la forma fundamental de asentamiento en la cuenca norte del Titicaca (Arkush 2009), cuya construcción es interpretada como una respuesta defensiva a los riesgos generados por la fragmentación política de este territorio en el periodo Intermedio Tardío. La violencia de las acciones de guerra se convierte así en el motor del desarrollo cultural que registra la arqueología (Vencl 1983; 1984; Thorpe 2003).

La construcción de murallas con simbolismo militar, como debían de ser los muros de Saqsaywaman, ha sido relacionada con las batallas rituales o tinku propias de la tradición andina (Zuidema 1991; Urton 1993; San Martín 2002). Santa Cruz Pachacuti (1968 [1613]: 299) narra una batalla ritual de asalto a Saqsaywaman, que habría tenido lugar ante el propio Pachacuti, en la cual su nieto Huayna Capac al frente de «sus cincuenta mil hombres, todos armados de oro y plata» habrían combatido «a manera de comedias», hasta vencer «a los que estauan fortalezidos en Sacssaguaman, y entrando a la fortaleza, saca a todos... y las cabecas cortadas, que estauan para esse efecto hechas, les unta con sangre de llamas y pone en las lancas». Tinku significaba el simbolismo del sacrificio humano sangriento que renueva la tierra y propicia el éxito de las cosechas. En el caso de Saqsaywaman aporta una explicación funcional a la construcción de murallas con finalidades ceremoniales (Molinié-Fioravanti 1988). La referencia de Pachacuti Yamqui al uso de las cabezas cortadas en Saqsaywaman enlaza con la larga discusión sobre las mismas en la historiografía nazca (Divale 1973; Proulx 1989; Kellner 2001: 90).

En realidad, la oposición entre «ceremonial» y «militar» es una falsa dicotomía, tal como nos lo muestra el ejemplo de Saqsaywaman: el conjunto servía de almacén de pertrechos de guerra, por lo que en algún modo tenía funciones militares, $\mathrm{y}$, sin embargo, no era una fortaleza porque nunca tuvo una guarnición militar profesionalizada y nunca estuvo pensada para resistir un asedio. De hecho, los asedios prolongados fueron pocos durante la expansión bélica de los incas: Cayambis, Huamanga, Chichas, tal vez Cerro Baúl y el conocido episodio de la conquista de valle de Cañete que duró cuatro años (Arkush y Stanish 2005: nota 13). En resumen, la ambivalencia 
de Saqsaywaman nos ayuda a intuir las complejas relaciones entre ciudad, asentamiento ceremonial y recinto fortificado en la tradición andina.

A continuación presentamos los resultados del estudio arquitectónico del sector de Muyukmarca. El trabajo de campo se llevó a cabo durante el seminario de Arqueología de la Arquitectura realizado en 2010 en el $\mathrm{Cusco}^{5}$, el cual permitió recopilar los datos topográficos y la documentación fotográfica necesaria para construir un modelo 3D del conjunto arqueológico. Como sólo contamos con los cimientos de los antiguos edificios, que además están dispuestos en la pendiente del cerro, el modelo 3D ha sido un instrumento fundamental para el análisis arquitectónico. Así, el razonamiento arqueológico y las hipótesis de reconstrucción se apoyan en la documentación gráfica generada a partir de este modelo y que presentamos en estas páginas. Planos, alzados, secciones y perspectivas han sido dibujados en el Seminario de Topografía Antigua de la URV-Tarragona (2011-2013) a medida que progresaba el análisis de los edificios. El grafismo final ha sido realizado por los autores del artículo.

\section{Las terrazas y muros perimetrales de la colina}

Los célebres muros megalíticos en forma de zigzag que forman los límites de la colina hacia el norte y hacia el este son todavía hoy el rasgo más conocido del conjunto (Lee 1986). No llegaron a ser completados y se hallaban todavía en construcción a la llegada de los españoles (Protzen 1987-89). Son tres muros que presentan una sección similar: su parte inferior (1-2 m) funcionaba como muro de contención mientras que el resto de su alzado era un grueso muro exento de varios metros de altura con un paso de ronda en su parte más alta. Tres caminos diferentes atravesaban los muros. Sin embargo, fueron construidas quince puertas, muchas más de las necesarias para permitir su paso. Garcilaso (2004 [1609]: 485) cita los nombre de algunas de ellas y recuerda que cada puerta se cerraba con un bloque levadizo. Una reciente excavación arqueológica realizada en el Cusco (Calle Suecia) ha descubierto el basamento de una puerta asociada con varios muros de contención en zigzag similar a los de Saqsaywaman (Farrington 2010: 93). Estas puertas estaban cubiertas con grandes dinteles monolíticos proporcionados a la dimensión de los bloques utilizados en la construcción de los muros. Un sistema constructivo similar al que encontramos en la gran puerta de la denominada «muralla» de Pisac, en el acceso monumental al recinto alto de Machu Picchu y en la entrada con dintel monolítico que controlaba el acceso a la parte alta del conjunto sacro de Ollantaytambo. En los tres casos, han sido descritas

\footnotetext{
5 El seminario de Arqueología de la Arquitectura se realizó en cooperación entre la Universidad Nacional San Antonio Abad del Cusco (UNSAAC) y la Universitat Rovira i Virgili de Tarragona (URV), España (20102011), financiado por la Agencia Española de Cooperación y Desarrollo (AECID: CAP-2009-1300). El grupo de trabajo estuvo formado por Ing. José Carlos Ramírez y Dr. Cayo García (UNSAAC), Dr. Ricardo Mar, Dr. J.A. Beltrán-Caballero, Dr. Igor Parra y Arq. Carolina Aguilera (URV). Por otra parte, los datos topográficos se han integrado en el proyecto «Visualizing Cusco» que agrupa la Municipalidad del Cusco (Arq. Crayla Alfaro), el National Museum of the American Indian del Smithsonian Institution, Washington (Dr. Ramiro Matos) y la Universitat Rovira i Virgili para la reconstrucción de la imagen visual de la capital imperial del Cusco inca y su aplicación en la exposición «The Great Inka Road» (Washington, junio de 2015). Los resultados completos de todo ello pueden consultarse en la página web de nuestro grupo de investigación (www.setopant.com).
} 


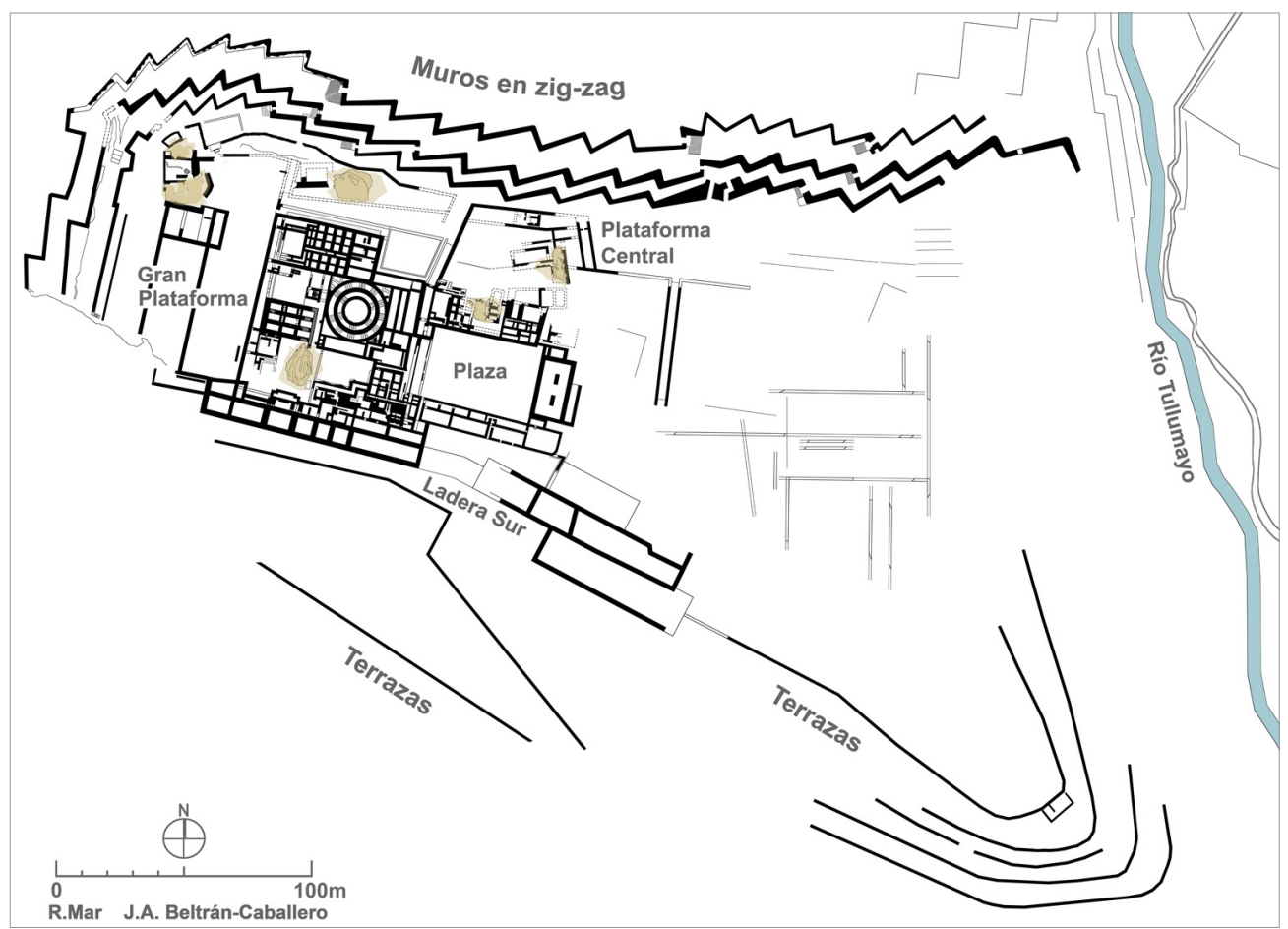

Figura 2: Planta general de los restos de Saqsaywaman.

(Dibujo: Ricardo Mar y José Alejandro Beltrán-Caballero).

como puertas defensivas (Kaufmann y Kaufmann 2006). Sin embargo, forman parte de recintos que no fueron cerrados como murallas, por lo que deberíamos pensar que servían para fijar límites monumentales a espacios y territorios sacralizados.

La construcción de quince puertas en los muros de Saqsaywaman nos permite intuir que el conjunto respondía a finalidades más complejas que el simple acceso a la cumbre del cerro o su defensa militar (Arkush y Stanish 2005). La forma en zigzag de los muros ha sido puesta en relación con la divinidad del rayo (Silva 2007), aunque Garcilaso de la Vega, impulsado por sus motivaciones familiares, sugiere una relación con el arco iris (Mazzotti 1996: 182). Dada la complejidad arquitectónica del conjunto, es probable que tuviese un simbolismo religioso múltiple. La disposición alterna de las quince puertas debía permitir complejos rituales en el acceso a la ciudadela que sobrepasaban la mera batalla ritual o tinku que cita Pachacuti Yamqui. Aunque el desarrollo específico de estos rituales nunca podrá ser precisado con los meros datos arqueológicos, existen algunos paralelos que pueden sugerir el posible uso ceremonial de los recorridos en zigzag. En particular, el que describe Garcilaso de la Vega (2004 [1609]: 134) en el interior de la gran kallanca del santuario de Viracocha en Raqchi. Tanto el edificio como el recorrido ceremonial (vid. Gasparini y Margolies 1977: 243, 250-51) han sido entendidos a partir de datos arqueológicos como parte de las ceremonias que allí se realizaban en honor del gran creador (Sillar 2002: 221-246). A pesar de la dificultad que genera el texto de Garcilaso, sabemos 
que la liturgia incluía un recorrido en zigzag atravesando alternativamente ocho puertas abiertas en el muro central del edificio.

En Saqsaywaman, los muros en zigzag se prolongan en sus extremos mediante terrazas que abrazan completamente el perímetro de la colina (Figura 2). Lo que coincide con la descripción de las «tres cercas» que escribió Garcilaso (2004 [1609]: 483). El resultado es una gran meseta rodeada por laderas construidas que dibujaba en planta un alargado cuadrilátero irregular. Algunos muros están asociados con niveles de cronología kilke (Rowe 1944). Las terrazas de la pendiente, actualmente cubiertas por tierra y vegetación, descendían hasta enlazar con los barrios más altos del antiguo Cusco en la zona de la iglesia de San Cristóbal, antiguamente denominada Qolqanpata (vid. Figura 1). Allí se han conservado los restos de un edificio que sirvió de residencia a los últimos representantes de la estirpe real inca. Los muros del «palacio» se prolongan por la ladera con estructuras, canales y terrazas agrícolas hoy interrumpidas por la carretera asfaltada que sube al cerro (Valencia 1984). Incluye dos caminos incas que ascendían hacía Saqsaywaman («1» y «2» en la Figura 1). Si a todo ello añadimos que el topónimo de la zona responde a la antigua presencia de almacenes agrarios (qolcas) en este sector de la ciudad y la noticia de la existencia en este lugar de andenes rituales reservados para el cultivo ceremonial, podemos concluir que las terrazas de la ladera del cerro fueron la solución de continuidad que enlazaba Saqsaywaman con el centro urbanizado del Cusco. Así, la colina rodeada completamente de terrazas era visible desde todo el valle como un zócalo escalonado coronado por los edificios levantados en su cumbre.

\section{Las grandes unidades constructivas del Sector de Muyukmarca}

La cumbre de Saqsaywaman (Figura 3) nos aparece hoy en día como una colina transformada por la acción humana. Sin embargo, antes de ser completamente ocupada por terrazas y construcciones, presentaba un aspecto muy diferente; era una cresta rocosa irregular que dominaba la cabecera del valle (Kalafatovich 1970). Las grandes rocas que todavía hoy emergen entre los restos arqueológicos son testimonio de ello. Antes de asentar los cimientos de los edificios, fue necesario construir terrazas y muros destinados a estabilizar las pendientes del cerro y regularizar la superficie horizontal de su cumbre con un aporte masivo de tierras. El espacio fue organizado sobre la base de dos grandes plataformas (A y B) sostenidas por muros de contención. Cinco grandes elevaciones rocosas consideradas elementos sacros fueron integradas en el sistema de terrazas. Las cinco fueron trabajadas y sirvieron de soporte a pequeñas construcciones organizadas en torno a espacios descubiertos que rodeaban las rocas.

La primera de las rocas trabajadas («R-1» en la Figura 3) se sitúa en el extremo oeste de la colina, a espaldas de los muros en zigzag. Los restos conservados y las improntas labradas en la roca dibujan la planta de un conjunto de habitaciones adosadas a la roca, que dan forma a dos patios cerrados ( $\mathrm{A}$ » $\mathrm{y}$ «B $\mathrm{B}$ » en la Figura 4, con los restos arqueológicos y su restitución). La calidad de la mampostería empleada en la construcción, los enterramientos descubiertos en sus inmediaciones (Paredes 2007: 243) y la presencia de una fuente en el interior de uno de los patios (el B) permite 


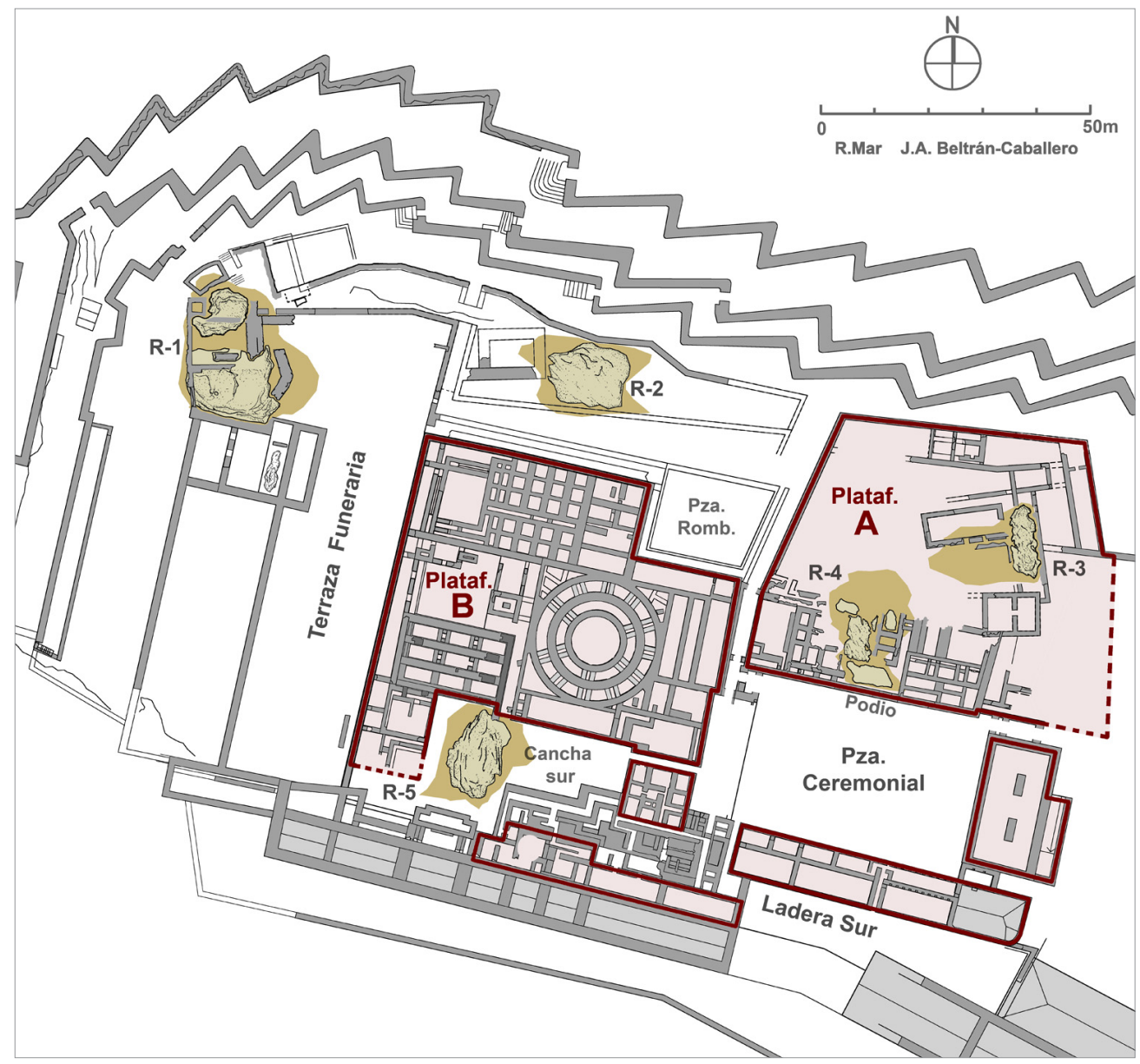

Figura 3: Principales unidades arquitectónicas del conjunto de Muyukmarca o Sector Occidental de la Colina. Se indican las cinco rocas (R-1 a 5), las dos plataformas, las tres plazas (Ceremonial, Romboidal y Cancha Sur) y las construcciones de la Ladera Sur, así como la terraza funeraria asociada a la huaca de la Roca 1. (Dibujo: Ricardo Mar y José Alejandro Beltrán-Caballero).

atribuir una función religiosa y ceremonial a este conjunto arquitectónico (Van de Guchte 1999; Staller 2008). La fuente está situada junto a una profunda hendidura en la roca que daba acceso a un sistema cárstico subterráneo que se extiende por debajo de las construcciones incas. La hendidura fue transformada en una galería («G» en la Figura 4) y sus paredes revestidas por muros de fina mampostería regular. Es bien conocida la importancia que juegan las cuevas en los mitos andinos de origen, común con otras culturas americanas como la mexica (Limón Olvera 1990). En nuestro caso, su asociación con una fuente de agua refuerza el valor religioso de este conjunto (Sherbondy 1995).

A cincuenta metros de distancia de este primer conjunto se sitúa la segunda roca que afloraba en la superficie de la colina ( $(\mathrm{R}-2 »$ en la Figura 3$)$. Aunque esta zona 


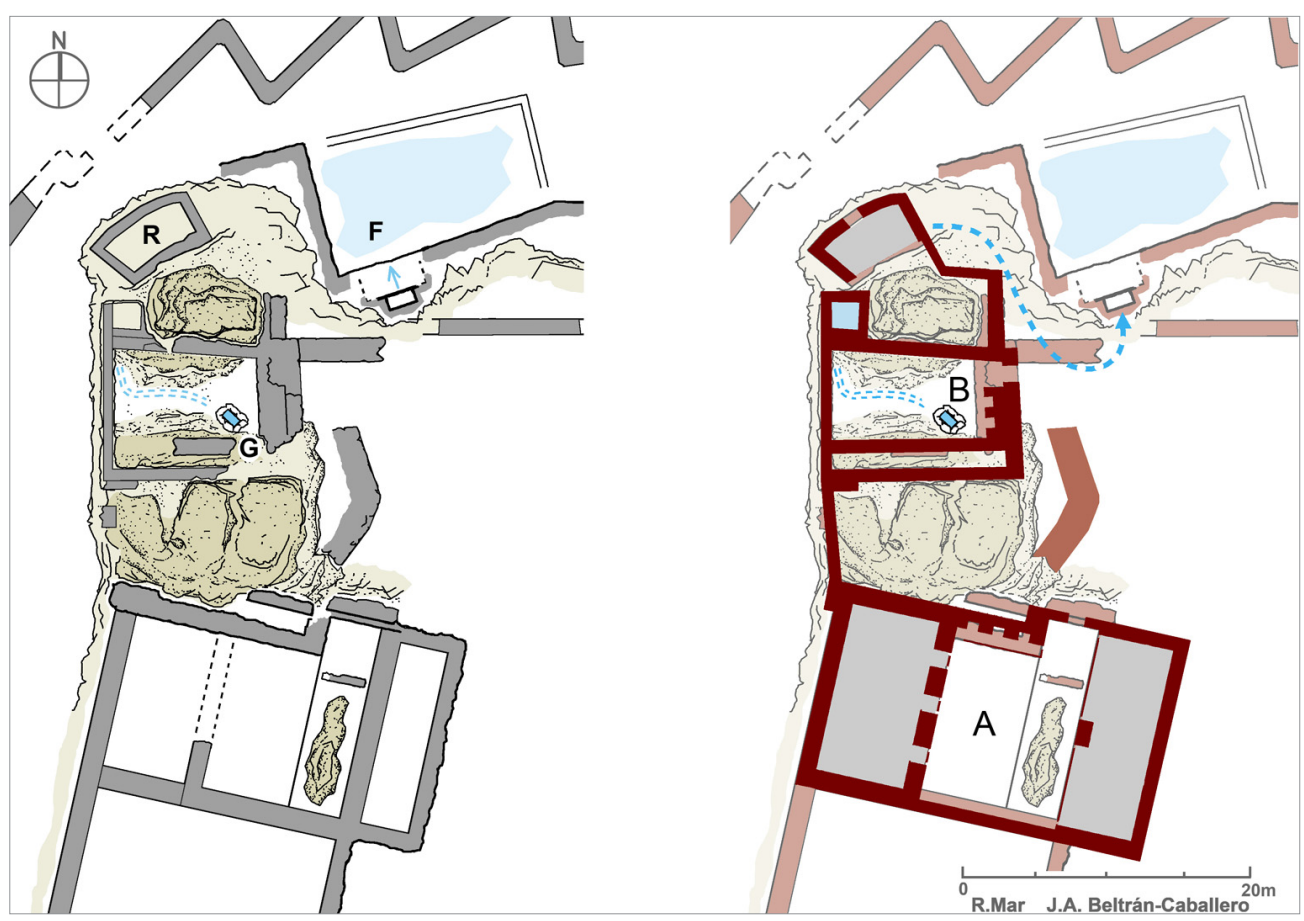

Figura 4: Restos arquitectónicos en el entorno de la Roca R-1 (izquierda) y su posible restitución (derecha). G: Galería de acceso al sistema cárstico; A y B: Patios adosados a las rocas; R: Reservorio; F: Fuente. (Dibujo: Ricardo Mar y José Alejandro Beltrán-Caballero).

no ha sido completamente excavada, es evidente su posición y su relación con un grueso muro (1,5 $\mathrm{m}$ de anchura) en forma de «T». La tercera y cuarta rocas («R-3» $\mathrm{y}$ «R-4» en la Figura 3) se sitúan en el interior de la Plataforma A. La primera es un bloque de gran desarrollo vertical y, por ello, los edificios construidos en su entorno fueron organizados en dos niveles superpuestos. En cambio, la segunda es una roca plana que aflora en la zona central y más elevada de la Plataforma. Su posición sirvió para fijar el límite de la Plaza Ceremonial (el «podio» en la Figura 3). En realidad, la zona rocosa que aflora irregularmente en el centro de la colina fue rodeada por muros de contención para transformarla en una extensa plataforma (la Plataforma A) con la forma de un trapecio irregular (vid. Figura 5, más adelante). En su interior se construyeron cinco edificios independientes destinados a usos religiosos y representativos, asociados con las rocas que afloraban en esta parte de la colina. El espacio libre entre los edificios fue regularizado y destinado a actividades artesanales de producción de objetos de prestigio, cuyos restos han aparecido en las últimas excavaciones (en 2011).

La Plataforma A sirvió para construir cinco edificios. En cambio, la Plataforma B albergó un solo edificio unitario del que se conservan sus cimientos (Edificio de los Torreones). Éstos dibujan tres cuerpos compactos, uno de ellos circular, que pro- 
bablemente corresponden a los «torreones» mencionados por Garcilaso de la Vega (2004 [1609]: 485-488) .

Las dos plataformas construidas fueron complementadas con tres plazas. La mayor de ellas era un gran espacio rectangular situado entre las dos plataformas (Plaza Ceremonial). Por otra parte, delante de la fachada sur del Edificio de los Torreones se construyó una pequeña plaza rodeada por construcciones (Cancha Sur). Finalmente, a espaldas de los muros en zigzag se delimitó una plaza de planta romboidal destinada probablemente a albergar unos jardines sacros (Plaza Romboidal). Para crear el espacio de la Plaza Ceremonial y de la Cancha Sur fue necesario construir dos cuerpos de edificación apoyados en las terrazas escalonadas que descendían por la Ladera Sur de la colina («Ladera Sur» en la Figura 2). Las tres plazas estaban comunicadas por pasillos y corredores que sirvieron para organizar las circulaciones entre las plataformas y los edificios construidos sobre la colina.

Finalmente, levantada más de cuatro metros respecto a los edificios de su entorno y situada en el extremo suroeste de la Plataforma B, se encuentra la quinta y última gran roca («R-5» en la Figura 3). Presenta signos de haber sido trabajada y conserva algunos restos de los muros que se adosaron a sus paredes verticales. Aunque es difícil reconstruir su antigua forma, los datos permiten intuir que estuvo rodeada de construcciones y que funcionaba como una plataforma elevada situada en un punto estratégico de la colina. Carecemos de indicios seguros para ubicar la escalera que permitía acceder al espacio superior.

\section{Huacas y plataformas}

La posición de las cinco rocas condicionó el trazado de los muros de contención que delimitan las dos grandes plataformas, el trazado de la Plaza Ceremonial y la posición de la Cancha Sur. Disponemos de tres argumentos arqueológicos para afirmarlo: en primer lugar, el trazado de los muros en zigzag fue definido a partir de la posición de las tres primeras rocas; en segundo lugar, los muros que delimitan la Plataforma A se apoyan en las rocas tercera y cuarta; en tercer lugar, la Plataforma B que sostiene el Edificio de los Torreones tuvo que ser encajada en el espacio triangular que quedaba entre las rocas 3, 4 y 5 .

En el caso de las rocas 1, 3 y 5, su gran desarrollo vertical hizo que las estructuras adosadas fuesen ganando altura hasta formar una construcción con varios pisos superpuestos. El principio estructural fue la combinación de obra construida con las paredes de la roca trabajada. Se trata de una arquitectura mixta que conocemos bien en diferentes yacimientos del entorno del Cusco, como Quenqo, Laqo, Inkiltambo, Rumiwasi o Pucapucara, todos ellos lugares de culto generados en torno a una huaca o manifestación natural percibida como una presencia sobrenatural. La mayor o menor importancia de la huaca determinaba la mayor o menor importancia de las

\footnotetext{
6 Valcárcel (2007 [1934]), en la publicación de las excavaciones, identifica el torreón de Sallajmarca, citado por Garcilaso, con el recinto rectangular que cierra la Plaza Ceremonial. Lo hizo porque aún no se había excavado todo el conjunto. Pensamos que el texto de Garcilaso «sugiere» que los tres torreones formaban parte de una construcción unitaria, lo que debería excluir la propuesta de Valcárcel.
} 
construcciones adosadas a la roca y los espacios generados para el desarrollo de las actividades religiosas (Meddens 1997; Staller 2008). La persecución de los cultos ancestrales andinos acometida por la administración española civil y religiosa, la conocida «Extirpación de Idolatrías» (vid. Duviols 1977), se ensañó particularmente en la destrucción de estas construcciones. Desaparecidos los muros, sólo nos han quedado improntas en la roca que no siempre permiten una lectura arqueológica clara (Staller 2008: 296). Así, no siempre es posible distinguir entre el término general de huaca, o lugar religioso de carácter genérico, el más restringido de ushnu, o plataforma dedicada a la realización de sacrificios, en particular líquidos, y el específico de intiwatana u observatorio solar provisto de un gnomon que permitía fijar las observaciones en el horizonte. En el caso de la Roca 1, la combinación de enterramientos, fuente y cueva subterránea en una construcción con dos patios y varias habitaciones, nos permite suponer que estamos ante una auténtica huaca dotada de personalidad religiosa propia y que contaba con personal dedicado a su servicio. Los datos son más ambiguos en el caso de las rocas 2, 3 y 4 . Sólo la Roca 5 aporta datos para su reconstrucción como una plataforma elevada destinada a la observación de los fenómenos naturales.

$\mathrm{Al}$ igual que los grandes apus que dominan el horizonte lejano o los rasgos del paisaje que coinciden con la orientación de los eventos cíclicos del firmamento (Urton 1981a; Ziółkowski y Sadowski 1989; Gullberg 2009), las rocas podían ser percibidas como manifestaciones sobrenaturales. De hecho, en los yacimientos incas son frecuentes los bloques rocosos que han sido respetados en el trazado de muros y terrazas, sin que podamos atribuir una explicación funcional a dicha circunstancia (Van de Guchte 1990). Con más razón aun, en la construcción de Saqsaywaman se debió observar una respetuosa atención a las rocas singulares. Como hemos visto, la forma, posición y dimensiones de cinco de ellas condicionó la disposición de las grandes plataformas destinadas a sostener los edificios del conjunto arquitectónico.

\section{Las construcciones de la Plataforma A}

Los restos del Edificio 1 forman un tejido complejo de muros y cimentaciones con diferentes orientaciones. Dibujan varios recintos aproximadamente rectangulares que forman un patio a varios niveles entorno a la Roca 3. El edificio contaba con un segundo piso construido con bloques de andesita. El arrasamiento que han sufrido las estructuras nos impide conocer con detalle su forma. Con todo, la pared rocosa ha conservado numerosas improntas de los muros que delimitaban el patio, por lo que es posible proponer una posible reconstrucción del mismo (Figura 5, «1»). El edificio número 2 se construyó sobre la superficie rocosa que aflora en el centro de la Plataforma A (Roca 3). Sólo se ha conservado una parte de sus cimentaciones. A pesar de ello, es posible restituir una retícula de nueve celdas que delimitan un edificio de planta cuadrada. Dado el reducido tamaño de las celdas, la irregularidad de su trazado, el grosor de los muros $(1,5 \mathrm{~m})$ y la ausencia de pavimentos, podemos deducir que estamos ante un zócalo de cimentación que incluía tirantes destinados a estabilizar los rellenos de tierra que sostenían el edificio sobre la superficie rocosa. En nuestro 


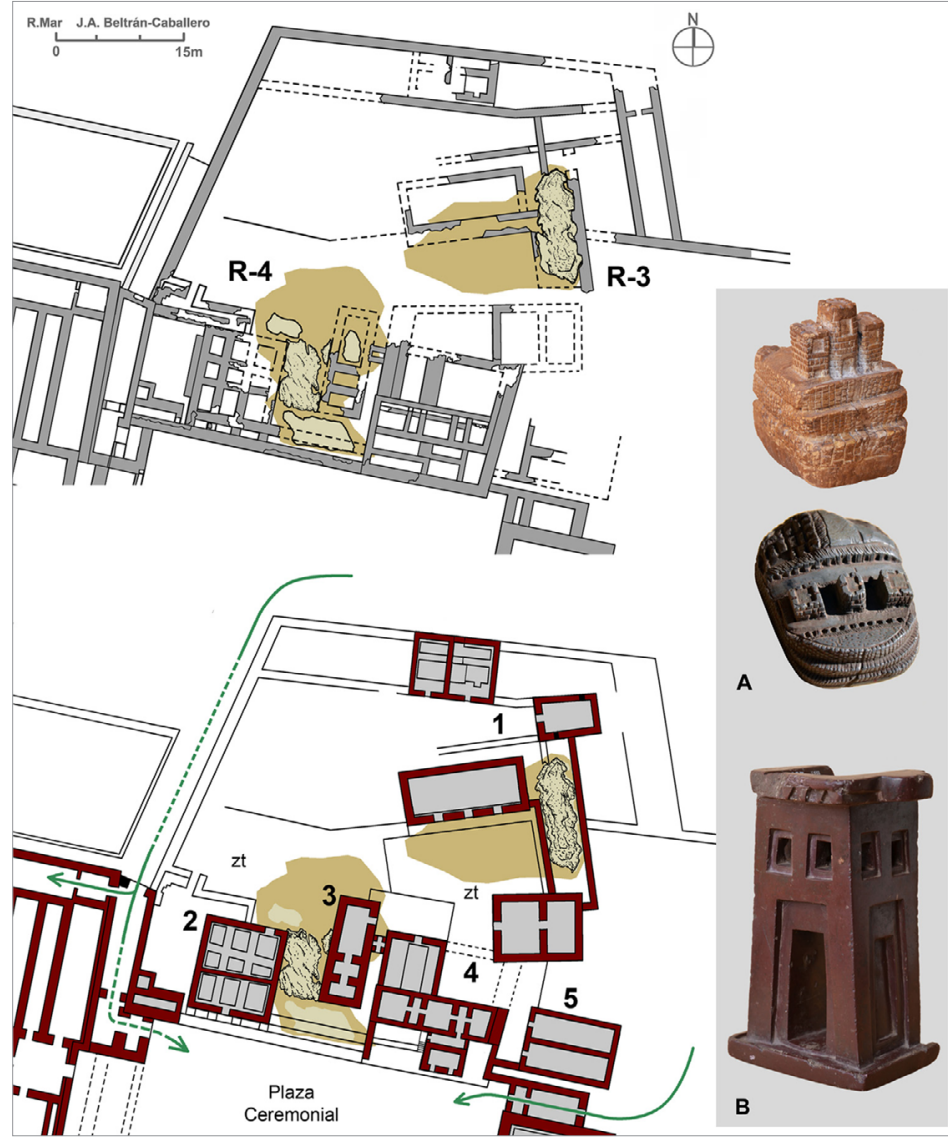

Figura 5: Elementos arqueológicos en la Plataforma $\mathrm{A}$, con los restos de los cinco edificios y su relación con la posición de las Rocas 3 y 4 (arriba). La reconstrucción que proponemos para los edificios (abajo) es confirmada por las maquetas incas conservadas en el Museo del Cusco (A y B). (Dibujo: Ricardo Mar y José Alejandro BeltránCaballero).

caso, debemos suponer que la planta principal del edificio estaba formada solamente por uno o dos espacios con un importante desarrollo vertical. Si además tenemos en cuenta la forma cuadrada de su planta, podemos imaginar su alzado como una torre similar a las representadas en las maquetas incas del museo arqueológico del Cusco (Agurto 1987: 274, 275 y 281; vid. Figura 5); dotadas de una importante puerta monumental, disponían además de un piso superior con ventanas y cubierta plana con un gran alero. El edificio número 3 es un edificio rectangular que ha perdido completamente su fachada norte. Dos muros internos dividían su interior en tres celdas de tamaño similar. El edificio número 4, a diferencia de los dos anteriores, presenta una planta mucho más compleja. La parte norte abraza un espacio descubierto («zt» en la Figura 5) que llegaba hasta los muros del Edificio 1. Ésta es una de las zonas de trabajo artesanal documentadas por las excavaciones arqueológicas. La parte sur, en cambio, se levanta sobre el podio que limita la Plaza Ceremonial. Finalmente citaremos la existencia de un último edificio (el 5) construido sobre la Plataforma A.

Si tenemos en cuenta la complejidad de los espacios construidos en torno a las rocas y las circulaciones a varios niveles, es posible suponer para estas construcciones usos ceremoniales. Estaríamos ante un caso análogo al que hemos reconstruido en 
el entorno de la Roca 1 (Van de Guchte 1990). La distribución de los cinco edificios muestra la complejidad funcional de los espacios construidos en la Plataforma A. Contamos con las construcciones ceremoniales asociadas con la Roca 3 (Edificio 1). A partir de las descripciones de las crónicas y por analogía con otras huacas mejor conservadas, podemos suponer que los espacios construidos junto a la roca servían para las normales funciones religiosas de este tipo de construcciones: mantenimiento y atención a la vida cotidiana de la huaca, ceremonias de consulta, custodia de fardos funerarios, depósito de objetos votivos y espacios destinados al alojamiento del personal adscrito a la huaca. En segundo lugar, tenemos los espacios centrales de la plataforma donde las excavaciones han descubierto restos de actividades artesanas de producción. Finalmente tenemos las construcciones que se alineaban frente a la fachada de la Plaza Ceremonial (Edificios 2, 3, 4 y 5). Fueron levantados sobre el muro de contención rectilíneo que forma la fachada norte de la plaza. Su construcción permitió regularizar el frente rocoso, completando con tierra aquellas zonas donde la roca descendía formando una hendidura natural. El resultado fue una terraza continua sobre la que se alzó la fachada de los cuatro edificios. Por sus características arquitectónicas debían configurar una imagen monumental y representativa hacia la plaza. Hemos citado las maquetas del Museo del Cusco como paralelo para su reconstrucción arquitectónica. Existe una maqueta en particular que presenta la imagen de tres torres yuxtapuestas sobre un zócalo unitario que sirve de referencia en la reconstrucción de este conjunto arquitectónico.

En conclusión, los datos arqueológicos permiten reconstruir una serie de «torres» que dominaban funcionalmente el espacio de la Plaza Ceremonial. Dado su reducido espacio interior y la importancia de sus cimentaciones, tenemos que pensar en una función representativa, tal vez asociada con su posición de dominio visual respecto a la plaza. Pudieron alojar objetos de prestigio religioso y por tanto político, que habrían sido exhibidos en ocasión de las fiestas y celebraciones que tenían lugar en la plaza. Sabemos que entre esos objetos se contaban los ídolos que pertenecieron a pueblos conquistados, algunos objetos excepcionales que expresaban un carácter sobrenatural, fardos funerarios de personajes relevantes, etc. Estos edificios, a pesar de su aparente simplicidad, fueron construidos siguiendo un sistema de relaciones espaciales complejas. Dado el terrible estado de destrucción en que se encuentran, es muy difícil reconstruir las motivaciones paisajísticas, astronómicas o simplemente funcionales que determinaron estas relaciones complejas.

\section{La Plataforma B y el Edificio de los Torreones}

Al fondo de la Plaza Ceremonial y dominándola visualmente, se alzaba el «Edificio de los Torreones» ocupando completamente la superficie de la gran terraza que hemos denominado Plataforma B (Figura 6). Para mantener su horizontalidad, fue necesario rellenar con tierra las irregularidades del substrato rocoso y construir un gran muro de contención de cuatro metros de altura, realizado con un paramento poligonal de bloques calizos. Aunque sólo se han conservado los cimientos del edificio y una parte importante del sistema hidráulico, contamos con las descripciones de los 


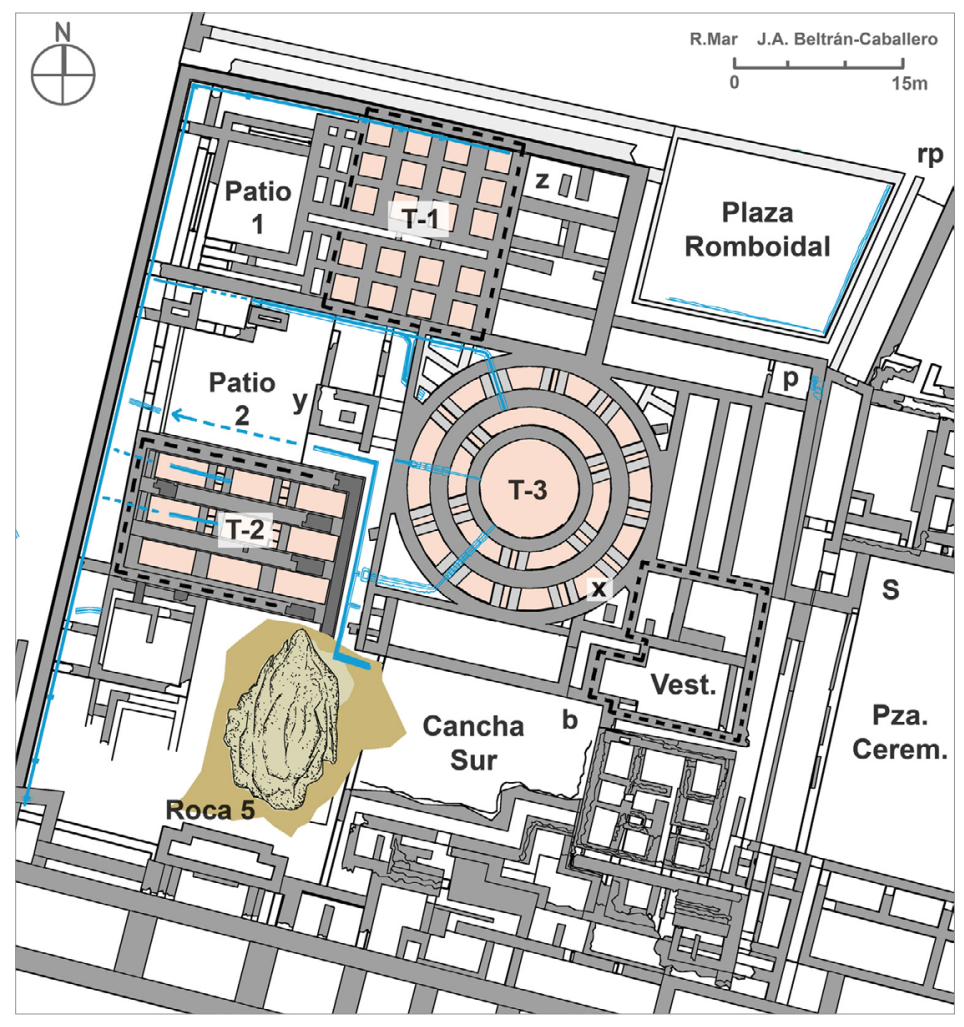

Figura 6: Restos de la Plataforma B (Edificio de los Torreones) y construcciones de la Ladera Sur. (Dibujo: Ricardo Mar y José Alejandro BeltránCaballero).

cronistas coloniales y con el análisis arqueológico de los restos para aproximarnos a su restitución.

Si consideramos las características estructurales de los cimientos del edificio, vemos, por una parte, una serie de muros de gran tamaño que por su grosor (en torno a $1,5 \mathrm{~m}$ ) pueden ser descritos como «muros estructurales». Fueron construidos sobre potentes cimentaciones y creemos que sirvieron para dibujar las líneas principales de los distintos cuerpos de edificación que formaban el edificio. Permiten distinguir el perímetro de los dos torreones rectangulares (T-1 y T-2) y la forma circular del torreón circular (T-3). Estos muros enlazan constructivamente unos con otros formando una red continua que se extiende sobre la superficie rigurosamente nivelada de la Gran Plataforma. En segundo lugar, tenemos una serie de muros secundarios de menor grosor $(c a .0,8 \mathrm{~m})$ que, en general, carecen de una cimentación diferenciada del propio muro. Desde el punto de vista arqueológico, se adosan a los muros estructurales y fueron realizados en una segunda etapa del proceso constructivo. Son de poca longitud (en torno a los 2-3 metros) y sirvieron para completar la distribución de las habitaciones interiores.

Las cimentaciones del torreón número 1 se identifican con claridad en la zona norte de la plataforma: dibujan una parrilla formada por pequeñas habitaciones cuadradas organizadas simétricamente en torno a un pasillo central. El torreón está asociado con un patio cuadrado («Patio 1» en la Figura 6) desde donde se accedía al pasillo y 
a partir de este a las cámaras interiores. Se dibuja así un sistema cerrado y fácilmente controlable desde un solo acceso central que encaja bien con las noticias coloniales acerca de la presencia de almacenes en Saqsaywaman.

Es cierto que el sistema de almacenaje de la producción agrícola que se guardaba en las qolcas se basaba con frecuencia en la repetición de células aisladas, tanto de planta rectangular como circular (Raqchi, Pumpu, Huanuco Pampa...). Pero también es cierto que, en otras ocasiones, las cámaras de almacenaje se integran en edificios de carácter masivo basados en la repetición modular de recintos. En el caso de Saqsaywaman, estos paralelos no resultan significativos ya que las fuentes coloniales (Sancho de la Hoz 1962 [1534]: 91) hacen referencia al almacenamiento «de armas, porras, lanzas, arcos, flechas, hachas, rodelas, jubones fuertes acojinados de algodón, y otras armas de diversas maneras, y vestidos para los soldados», objetos cuya gestión se aleja de las condiciones que imponía el almacenaje de productos alimenticios. El Patio Cuadrado (Patio 1), con sus dependencias alargadas, sería el espacio complementario idóneo para la manipulación de los bienes almacenados en las cámaras cuadradas.

Los cimientos del segundo «torreón» («T-2» en la Figura 5) se reconocen en el extremo oeste de la plataforma B. Se han conservado in situ algunos bloques de la primera hilada de sus paredes. Debía tratarse de un edificio de altísima calidad constructiva a juzgar por la calidad del acabado de los bloques escuadrados de andesita, que presentan sus caras vistas pulidas y constituyen la única documentación disponible para imaginar los alzados arquitectónicos del edificio. Estos restos dibujan dos puertas interiores y una que se abría en la fachada del edificio. Disponemos además de los muros secundarios, perpendiculares a los muros estructurales, que sugieren la división del interior en pequeñas habitaciones similares a las que hemos reconstruido en el Torreón 1. Teniendo en cuenta todo ello, podemos restituir la planta baja del edificio como un sistema de pequeñas habitaciones interconectadas y accesibles desde el exterior a través de una sola puerta. Nuevamente, nos encontramos con una configuración arquitectónica idónea para su utilización como espacio de almacenamiento de objetos y bienes.

El tercer «torreón» es el célebre edificio circular identificado por las fuentes escritas («T-3» en la Figura 6). Está formado por tres muros circulares concéntricos que delimitan una cámara interior de $9 \mathrm{~m}$ de diámetro y dos anillos, también circulares, de 1,5 y $1,8 \mathrm{~m}$ de anchura. El último muro circular se prolonga con muros que enlazan con los cimientos de los torreones rectangulares, de modo que todo el conjunto estaba englobado en una construcción unitaria que se extendía ocupando toda la plataforma.

A la hora de reconstruir el interior del Torreón Circular contamos con una serie de muros secundarios (tirantes) perpendiculares a los muros curvos. Están asociados en parejas y flanquean los restos de cuatro pequeños conductos de agua que nacen del espacio central y que se dirigen hacia el exterior del edificio. Dado que el mantenimiento de los canales debía exigir el acceso a los mismos para su limpieza o reparación, tenemos que suponer que su posición corresponde a pasillos de circulación fácilmente accesibles. Si restituimos estos pasillos, vemos que la planta baja del Torreón Circular se convierte en un pequeño laberinto formado por espacios curvos y pasillos rectos que conducía al centro del torreón mediante varios recorridos alternativos (Figuras 7 y 8 ). 


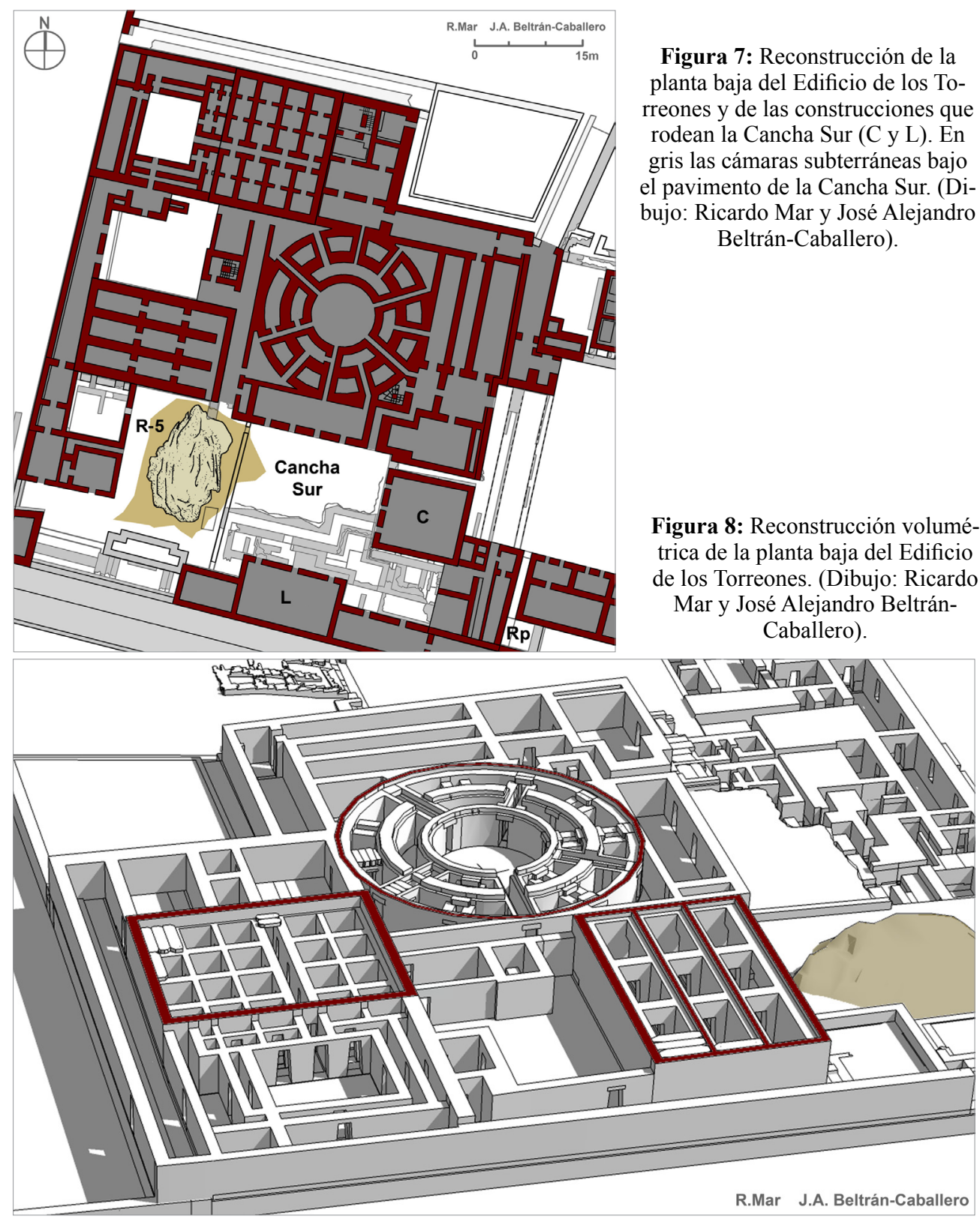

Los conductos hidráulicos han sido considerados como una prueba de que el espacio central era un reservorio de agua (Valcárcel 2007 [1934]), que debería corresponder a la fuente que cita Garcilaso en el Edificio de los Torreones: «había una fuente de mucha y muy buena agua, traída de lejos, por debajo de tierra» (2004 [1609]: 485). Desde nuestro punto de vista, la existencia de la fuente en el espacio central del torreón es incompatible con su interpretación como reservorio (en el sentido de un depósito de agua). 
En este punto, algunas características de los canales nos pueden ayudar a proponer una interpretación diferente. Existe un detalle constructivo asociado con el extremo final de uno de los conductos («c-1» en la Figura 6) que sugiere una interpretación distinta. Después de atravesar una de las paredes estructurales que delimitan el torreón circular, el conducto sale a $30 \mathrm{~cm}$ de altura sobre el suelo. En ese punto, la boca del conducto se convierte en un pequeño orificio de apenas $3 \mathrm{~cm}$ de diámetro. Si además tenemos en cuenta los restos de un pequeño depósito abierto $(40$ x $40 \mathrm{~cm}$ de lado), situado debajo de dicho orificio, podemos concluir que el conducto alimentaba una pequeña fuente dispuesta en un pasillo del edificio. Otros cuatro conductos similares procedentes del torreón circular vertían en este pasillo, aunque no han conservado el correspondiente bloque con el característico estrechamiento del primer conducto. Estas evidencias, consideradas conjuntamente, nos permiten reconstruir la posición de cinco fuentes que se abrían en la pared exterior del torreón. En resumen, en el centro del espacio circular se debería situar un punto privilegiado de distribución de agua que habría alimentado estas cinco fuentes exteriores. Si relacionamos esta propuesta con la información recogida en las crónicas coloniales, es inevitable situar en el centro del espacio circular la fuente ceremonial que menciona Garcilaso de la Vega. Para llegar a la fuente, habría sido necesario atravesar el laberinto de espacios circulares que hemos reconstruido en la planta baja del Torreón Circular.

La circulación de líquidos era un componente fundamental del sistema religioso inca focalizado en el culto de las huacas. Es bien conocida la asociación del vertido ceremonial de chicha en un ushnu con los pequeños conductos que conducían el líquido hasta la tierra (Meddens 1997; Pino Matos 2004; Staller 2008). Por ejemplo, en Chinchero y en Quenqo están excavados en la roca con un trazado zigzagueante. En el conjunto ceremonial de Tipón, situado a pocos kilómetros del Cusco, la circulación del agua es una de las características fundamentales del yacimiento (Wright 2006): la fuente que alimenta el sistema principal de canales incluye un sofisticado sistema de conducciones que primero multiplica las vías de agua para después reagruparlas, en un juego cuyo significado ritual desgraciadamente se nos escapa. Sin embargo, es el edificio ceremonial, también llamado Intiwatana, el que presenta mayores analogías con la planta baja del Torreón Circular de Saqsaywaman. El edificio de Tipón cuenta con tres patios interiores en los que se construyeron nichos de carácter monumental precedidos por plataformas rituales. Del fondo de cada nicho nace un pequeño canal que atraviesa la plataforma y prosigue por el pavimento del patio. La circulación del agua en el Torreón Circular debía de ser parecida: llegaba a la fuente situada en la sala central desde donde se dividía en cinco canales que circulaban por el pavimento de los pasillos para abastecer las cinco fuentes colocadas en el exterior del torreón.

La planta baja del Edificio de los Torreones se completa con un conjunto de habitaciones construidas en torno al Torreón Circular para formar las tres fachadas principales del edificio: una hacia la Plaza Ceremonial, otra hacia la Cancha Sur y la tercera hacia los jardines situados en la Plaza Romboidal. Estas habitaciones incluyen vestíbulos y los pasillos de acceso a las diferentes partes del edificio. Es posible determinar su posición gracias a restos conservados de las pavimentaciones. Se ha podido identificar el vestíbulo de acceso al edificio desde la Plaza Ceremonial («Vest.» en la Figura 6), el pasillo de acceso a la Cancha Sur («b» en la Figura 6) y el sistema de 
comunicaciones verticales. Este último elemento, a pesar de su rareza en el interior de los edificios incas, está perfectamente definido en Saqsaywaman: se trata de una habitación («Z» en la Figura 6) con un pilar central en torno al cual giran los peldaños de la escalera. Cuatro de ellos se han conservado in situ. El hueco de la escalera desciende por debajo de la cota de circulación de la Plataforma B y comunica directamente con la Plaza Romboidal, ubicada en el exterior del edificio. Contamos además con otras dos pequeñas habitaciones con un pilar interior que presentan una morfología similar y que tal vez tal alojaron sendas escaleras («x»e «y» en la Figura 6).

En definitiva, la planta baja del Edificio de los Torreones nos aparece como una yuxtaposición compleja de espacios de funciones diferentes. Aparecen bien definidos los espacios de almacenaje, que por su proximidad a los espacios ceremoniales del Torreón Circular, debían estar asociados con la conservación de productos de prestigio. Esta complejidad de funciones y usos implicó la gestión controlada de las circulaciones a través de un sistema de vestíbulos, pasillos controlados y posiblemente tres cajas de escalera para acceder al piso superior. En este sistema jugaron un papel fundamental los tres espacios descubiertos que flanqueaban el edificio: la Plaza Ceremonial, la Cancha Sur y la Plaza Romboidal. Las excavaciones en el interior de esta última han documentado un conducto hidráulico perimetral que puede ser interpretado como parte del sistema de irrigación del espacio interior. Este dato, unido a su singular posición, permite suponer que el recinto constituía un espacio agrario con una componente ritual, asimilable tal vez a una forma de jardín sacro.

\section{Las construcciones de la Ladera Sur}

Para construir la Plaza Ceremonial y la Cancha Sur fue necesario ganar espacio en la ladera de la colina. Como la roca natural descendía rápidamente, hubo que aportar un relleno de tierras para ampliar la superficie disponible y sostener la pavimentación horizontal de ambas plazas. Para contener el empuje que generaba este relleno se construyeron dos edificios adosados a la pendiente. Ambos se apoyaron en una terraza situada a una cota más baja que las dos plazas. Las habitaciones de la planta baja forman una doble hilera de cámaras accesibles desde la terraza inferior, dotadas de nichos en sus paredes. Sobre ellas se debía situar un segundo piso destinado a formar la fachada de la plaza. Valcárcel (2007 [1934]: 67) reconoce un escalón en algunas de las paredes que habría servido de ménsula para apoyar el envigado del piso superior. En Ollantaytambo y en Tipón contamos con construcciones apoyadas en terrazas de ladera que contaban con dos pisos superpuestos. También conocemos ejemplos similares en Machu Picchu y Choquequirao. Sin embargo, la escala y dimensiones de esta construcción sólo es comparable con las construcciones de varios pisos que flanquean la Plaza Ceremonial de Huch'uy Cusco. Allí, como en Saqsaywaman, los edificios que bordean las respectivas plazas ceremoniales fueron realizados sobre cámaras situadas a una cota más baja que el pavimento de la plaza. En este sentido, el templo del Sol en el Santuario de Pachacamac nos ofrece una solución arquitectónica comparable con el uso de bloques de edificación de dos pisos de altura, adosados a un muro de contención que delimita una plaza situada a una cota superior. 
En resumen, la construcción de un sistema de cámaras y pasillos subterráneos generó el espacio necesario para delimitar la Plaza Ceremonial y una Cancha delante de la fachada sur del Edificio de los Torreones. Esta última plaza se extendía junto a la Roca 5 y quedó delimitada por dos edificios que podemos reconstruir encima de las habitaciones de la Ladera Sur (Cancha Sur en la Figura 7). Es posible asociar este sistema de cámaras subterráneas con las referencias de las fuentes escritas a los «laberintos subterráneos» (Garcilaso de la Vega 2004 [1609]: 486). La reducida dimensión de los espacios habría permitido su techado con losas monolíticas (así lo indicamos en la reconstrucción, Figura 8), una solución constructiva que conocemos en los puentes del río Saphi (Agurto 1987) y que en los Andes tenía una larga tradición que se inicia con las construcciones de Chavín de Huantar (Gasparini y Margolies 1977: 167). Como en otros lugares de la colina, la excavación arqueológica de algunas de las cámaras descubrió restos de actividades productivas relacionadas con la fabricación de objetos suntuarios.

\section{Reconstrucción del piso superior del Edificio de los Torreones}

Hemos comentado ya los restos que documentan la presencia de una escalera dentro del Edificio de los Torreones («z» en la Figura 6). Su posición en el interior del edificio es una excepción en la arquitectura inca (Gasparini y Margolies 1977: 145). En Saqsaywaman es un indicio sólido de la existencia de un piso superior, como lo son también los bajantes de evacuación de agua pluvial que se han conservado en puntos muy alejados del edificio («b» en la Figura 6). Estos datos arqueológicos no son los únicos argumentos disponibles para reconstruir la desaparecida planta superior del Edificio de los Torreones; contamos además con algunos datos recogidos en las fuentes coloniales.

Las primeras descripciones de Saqsaywaman son aportadas por Cieza de León (1988: 88): «había muchos aposentos... unos encima de otros, pequeños, y otros entre suelos, grandes... y debajo de tierra dicen que hay mayores edificios». Estas referencias coinciden con la descripción de Sancho de la Hoz (1962 [1534]: 89-91): «hay una fortaleza de tierra y de piedra muy hermosa; con sus ventanas grandes que miran a la ciudad y la hacen parecer más hermosa. Hay dentro de ella muchos aposentos y una torre principal en medio hecha a modo de cubo, con cuatro ó cinco cuerpos, uno encima de otro: los aposentos y estancias de adentro son pequeños». Los aposentos pequeños deberían ser las cámaras de la planta baja, mientras que las ventanas grandes se deberían situar en el piso superior. Garcilaso nos transmite una imagen similar (2004 [1609]: 485-488): «Pasadas aquellas tres cercas [los muros en zigzag], hay una plaza larga y angosta, donde había tres torreones fuertes, en triángulo prolongado, conforme al sitio. Al principal de ellos que estaba en medio, llamaron Móyoc Marca; quiere decir: fortaleza redonda, porque estaba hecho en redondo... Al segundo torreón llamaron Páucar Marca, y al tercero Sácllac Marca; ambos eran cuadrados». La plaza «larga y angosta» es sin duda la Plaza Ceremonial, mientras que los tres torreones han de identificarse con los que hemos descrito en las páginas precedentes. El texto añade finalmente que «debajo de los torreones había labrado, 
debajo de tierra, otro tanto como encima; pasaban las bóvedas de un torreón a otro, por las cuales se comunicaban los torreones, también como por cima». Nuevamente se confirma la existencia de una planta superior de la que sobresalían en altura los tres «torreones», que eran vistos por los españoles como cuerpos escalonados. Además cita las «bóvedas» que cubrían los techos de esta planta baja («de un torreón a otro»), que más adelante son descritas con mayor precisión: «no supieron hacer bóveda de arco... dejaban para los soterraños unos canecillos de piedra, sobre los cuales echaban, en lugar de vigas, piedras largas, labradas a todas seis haces, muy ajustadas, que alcanzaban de una pared a otra».

La posición más probable de los salones en el piso superior es encima de la malla de pequeñas habitaciones dedicadas a almacenaje. Sus límites deberían coincidir con el perímetro que forman los muros estructurales en la planta baja. Es una solución constructiva poco frecuente, pero que cuenta con algunos antecedentes en la arquitectura andina, como el conjunto de Monqhachayoq («Lugar de las Monjas») en la gran capital wari (Pérez Calderón 1990; Isbell 2001; 2006). El edificio, asociado con usos funerarios, contaba con dos niveles superpuestos de cámaras de reducidas dimensiones (1,5-2 m), cubiertas con losas monolíticas y rodeadas de un grueso muro perimetral (Pérez Calderón 2000: 505). Este muro formaba un espacio unitario (12 x $6 \mathrm{~m}$ ) situado sobre las cámaras enlosadas. Monqhachayoq, aunque fue construido varios siglos antes del dominio inca, ofrece un modelo interpretativo compatible con la reconstrucción que sugieren los textos coloniales de los Torreones 1 y 2 de Saqsaywaman. Este mismo modelo estructural lo encontramos ya en época inca, en el denominado «palacio» de Pilco Kaima en la isla del Sol del lago Titicaca (Gasparini y Margolies 1977: 270). Se trata de una malla formada por doce habitaciones, cubiertas con falsas bóvedas por aproximación de hiladas, que sostiene un segundo piso ocupado por tres grandes espacios dotados de sus propias ventana y accesos independientes.

Si los «torreones» cuadrados presentan dificultades interpretativas, el «torreón» circular es un enigma aún mayor por la complejidad estructural de sus restos. Edificios circulares formados por anillos concéntricos (concentric ring sites) son escasos en la arquitectura inca, aunque son más frecuentes de lo que habitualmente se piensa en los territorios de la Sierra Norte del Perú. Desde la Puna de Junín (Parsons et al. 2000) al Callejón de Huaylas (Herrera 2005), pasando por la excavación de la estructura monumental denominada Construcción Circular Rondán (Terada 1979) o el reciente programa de investigación en el asentamiento de Yayno (Ancash) en la cuenca del río Marañón (Lau 2010: 428), se han dado a conocer en el último decenio numerosos edificios de planta circular que inciden necesariamente en esta discusión. Los ejemplos documentados subrayan el carácter público de estos edificios, destinados a ceremonias colectivas y asociados con procesos de ocupación prolongados en el tiempo.

Arqueológicamente sólo conocemos una construcción inca en la región del Cusco que, por su forma y dimensiones, se podría relacionar con las cimentaciones de Saqsaywaman. Se trata del edificio circular de Runku Raqay (Anglés Vargas 1972: 352-356), situado en un punto estratégico de la quebrada del Pakaymayu, desde donde controlaba una de las vías de acceso a Machu Picchu. Cuenta con un espacio 
Figura 9: Interpretación volumétrica del proceso de reconstrucción del Edificio de los Torreones. A: Restitución de la planta baja; B: Volumetría de la primera planta; C: Volumetría de los torreones.

(Dibujo: Ricardo Mar y José Alejandro Beltrán-Caballero).

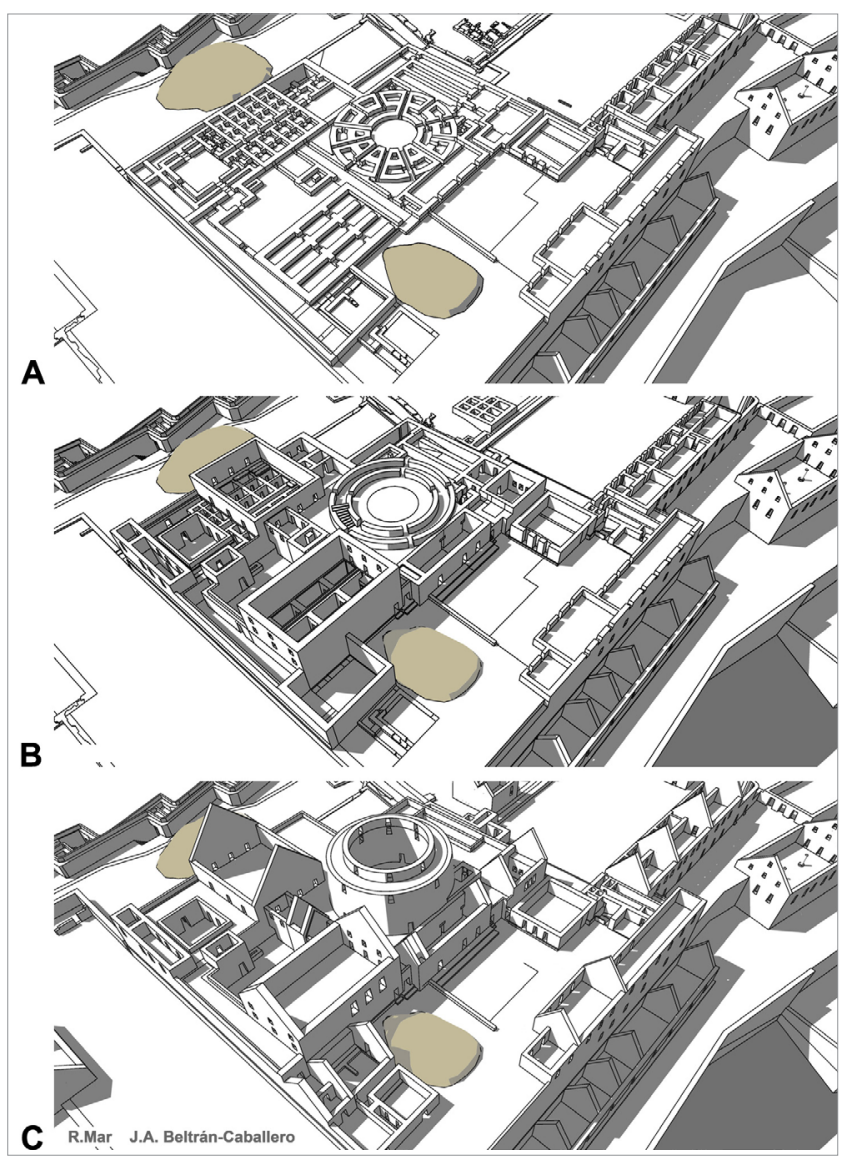

circular interior de $10 \mathrm{~m}$ de diámetro, rodeado por un anillo construido de $5 \mathrm{~m}$ de anchura, de modo que el tamaño completo del edificio alcanza los 19,4 m. El anillo está dividido en tres habitaciones casi iguales con nichos en sus paredes, separadas por tres estrechos corredores, uno de los cuales servía de acceso al edificio. Dado que en su entorno se han documentado restos de otras construcciones de menor calidad, se considera que el edificio circular era el punto focal de un huch'uy tampu, pequeño establecimiento en el camino que servía como lugar de vigilancia y estación de descanso. El espacio interior del edificio se considera habitualmente un patio descubierto, aunque por sus dimensiones habría podido soportar una cubierta de madera y paja. Esta es, en definitiva, la problemática que plantea la restitución de los pisos superiores sobre cimientos circulares de Saqsaywaman: saber si el edificio fue pensado y construido en función de un gran espacio interior cubierto o si, por el contrario, los anillos concéntricos de cimentación reflejan una serie de cuerpos escalonados al aire libre (kancha circular).

La primera línea de interpretación (un gran espacio interior cubierto) está apoyada por dos ejemplos de los que no tenemos ningún resto, pero que son citados por las fuentes coloniales. Garcilaso de la Vega (2004 [1609]: 60-61) describe un «hermo- 


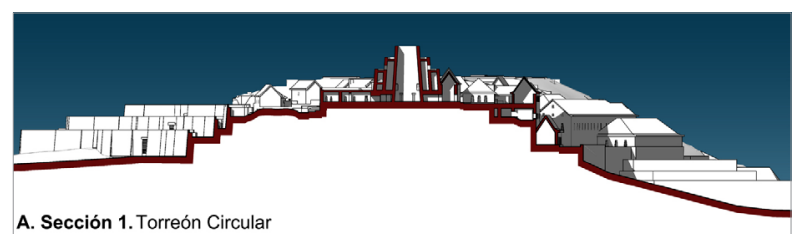

A. Sección 1. Torreón Circular
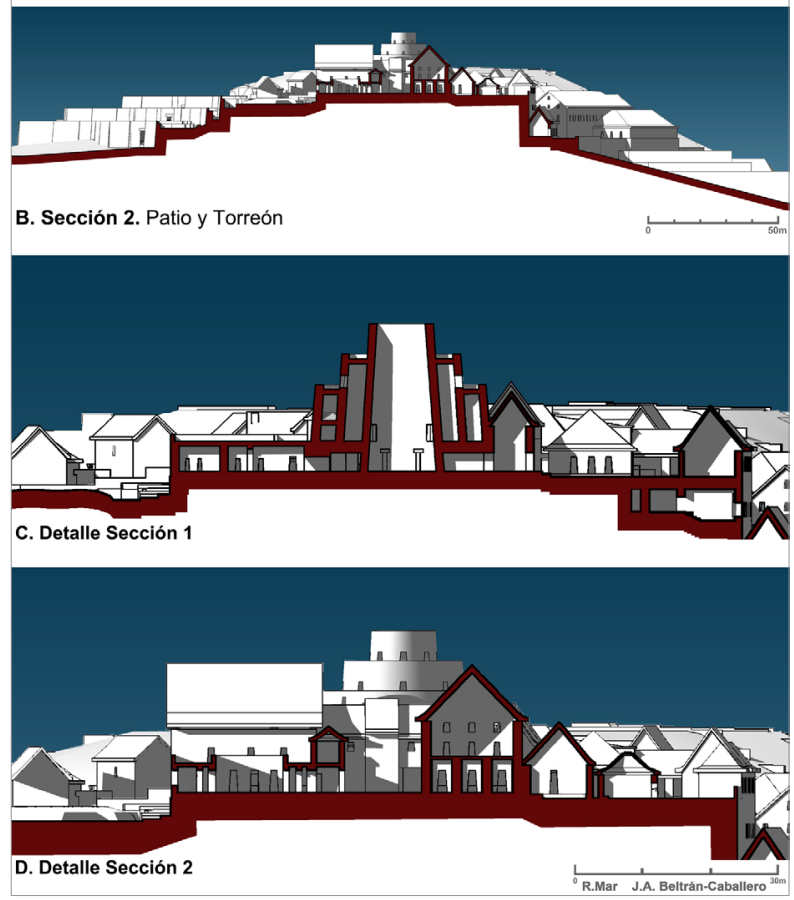

Figura 10: Edificio de los Torreones: secciones reconstructivas del torreón circular (A y C) y uno de los torreones de planta poligonal (B y D) que incluyen las terrazas superiores de la colina. (Dibujo: Ricardo Mar y José Alejandro Beltrán-Caballero).

sísimo cubo» circular cuyo interior estaba ocupado por un espacio de más de quince metros de altura. Estaba situado en la plaza de Awkaypata, delante del Amarucancha. El segundo ejemplo se encontraba junto a la calle del Triunfo, en el costado oriental del Kiswarkancha, «palacio» del propio Inka Wiraqocha (Bauer 2008: 237); era un gran edificio circular denominado Suntur Wasi que habría servido de «casa de armas y escudos». Aunque ambos edificios han desaparecido completamente, podemos aproximarnos a su imagen a partir de dos fuentes iconográficas indirectas. La primera es la lámina 329 del libro de Guamán Poma de Ayala (1980 [1615]: 331) con la representación de los «Palacios Reales, Casas de los Inca (llamadas) Cusimanco». Entre los distintos edificios que forman el conjunto palacial, destaca en primer término un edificio circular designado como suntor uaci (torre redonda), con ventanas en el segundo piso y techado con una cubierta cónica de paja. El modelo arquitectónico tiene su reflejo en un edificio circular ilustrado por Squier (1877: 394) en el pueblo de Azángaro, en la cuenca del lago Titicaca. Aunque el edificio no se ha conservado, nos queda una fotografía, un grabado y dos acuarelas con su representación (McElroy 1986). Como subraya Brian S. Bauer (2008: 233 y ss.), el edificio de Azángaro es el mejor paralelo para aproximarnos a los sunturwasi de la plaza del Cusco, a lo 
que nosotros añadimos que tal vez podría ser un referente para el Torreón Circular de Saqsaywaman.

La segunda línea de interpretación (que la torre circular fuera un cuerpo escalonado con terrazas planas) implica considerar que el edificio fue construido como parte de un sistema de observación astronómica. La medición rigurosa del movimiento del sol y de los astros en la línea del horizonte permitía establecer el calendario agrario y determinar las etapas del ciclo ceremonial que organizaba la vida cotidiana de la sociedad inca (Urton 1981a; 1981b). Para ello se procedía a la fijación de lugares privilegiados de observación y a la construcción en lugares significativos del horizonte de marcadores que sirviesen de referencia en las mediciones (Aveni 1981; Zuidema 1981). Sabemos que la plataforma sagrada o ushnu de Waykaypata habría servido como punto de observación para medir el paso del sol entre dos pilares llamados $\mathrm{Su}$ canca, construidos en la línea del horizonte del valle (Zuidema 1981: 320-321; 2007; 2008). En opinión de Zuidema (1981: 323-324), la torre del Sunturwasi del Amarucancha habría sido utilizada como indicador o gnomon por su forma esbelta y por acabar en un pináculo vertical. En este contexto, los edificios más representativos del Cusco, como el Coricancha, habrían sido trazados considerando las alineaciones del sol en el horizonte y en función de determinadas orientaciones astronómicas. Dada la relevancia de las construcciones de Saqsaywaman, podemos suponer que la posición del «torreón circular» y la forma de su alzado fueron determinadas por consideraciones de observación astronómica, lo que haría verosímil su reconstrucción como una serie de plataformas concéntricas escalonadas cubiertas con techos planos y tal vez coronadas por un pináculo. Tenemos un modelo arquitectónico en las terrazas concéntricas que dan forma a la sucanca del conjunto arqueológico de Choquekiraw Pukio en las inmediaciones del Cusco (Zecenarro 2001: 246). Se trata de un conjunto de terrazas concéntricas que dibuja un volumen cilíndrico escalonado, asociado con dos bloques de piedra utilizados como gnomon en las mediciones solares?

En conclusión, la extensa red de cimientos que hemos descrito constituía el soporte unitario de un único edificio que englobaba tres torreones y dos patios interiores. Es muy probable que en su trazado y construcción jugasen factores de observación astronómica que por ahora resulta difícil precisar. El sistema de circulación de agua y los restos de pavimentación nos han permitido precisar la posición de los pasillos de circulación. La planta baja formaba un tejido complejo y compacto de habitaciones articulado por pasillos, en la que almacenes y espacios ceremoniales de forma laberíntica se integraban en dos patios interiores. Encima se debía elevar un segundo

7 El cuadro de escuela cusqueña «Aparición de la Virgen en el Cusco» o «Milagro del Sunturwasi» que desde 1935 pertenece al Museo Enrique Udaondo de Luján (Provincia de Buenos Aires), aporta un punto de vista iconográfico para la reconstrucción del Muyukmarca. La obra habría pertenecido en su día a la Capilla del Triunfo o tal vez al coro de la catedral, antes de ser descubierta en Argentina en 1910. En ella se representa el descenso de la Virgen María en protección de los españoles asediados por las tropas de Manco Capac (Alcalá 1999: 180; 2004: 150-52). El autor pintó en el ángulo superior Saqsaywaman como una estructura circular escalonada con cubiertas planas. El problema de su uso como argumento topográfico es parecido al que presenta el torreón circular consolidado como símbolo de Sasaywaman en el escudo de armas concedido al Cusco en 1540 (Ramos Gómez 2004: fig. 1, tomada de Esquivel y Navia). Si se confirmase una cronología antigua para este cuadro (primera mitad del siglo XVII [Schenone et al. 1994: 119-125]), ganaría fuerza como argumento para interpretar el Muyukmarca como un observatorio escalonado o sucanca (vid. Figuras 10 y 11), dando mayor validez a la segunda de las hipótesis que hemos planteado. 


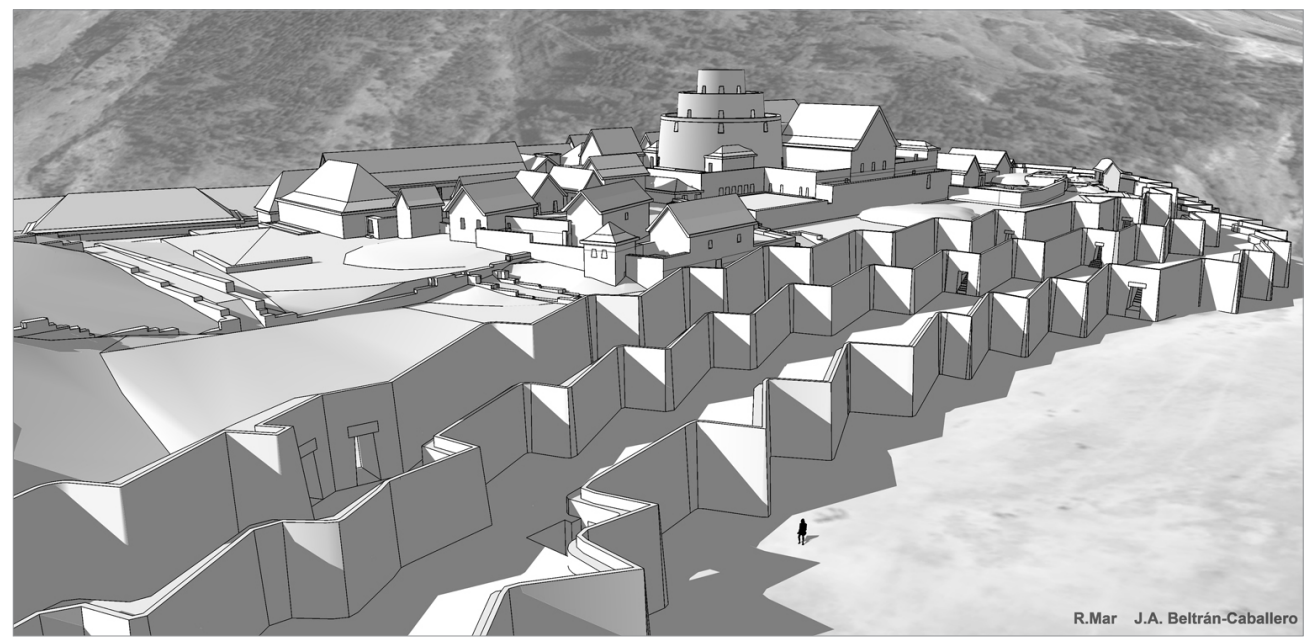

Figura 11: Reconstrucción volumétrica del Conjunto de los Torreones.

(Dibujo: Ricardo Mar y José Alejandro Beltrán-Caballero).

piso que contaba, al menos, con tres bloques de edificación en altura (los «torreones») que, a juzgar por las fuentes escritas, debían aparecer como las torres de homenaje de los castillos europeos tardo-medievales: exentas. Si esto fuera cierto, el piso superior debería estar ocupado, en parte, por una terraza que permitiera la comunicación entre los tres torreones. Hemos señalado ya la única escalera interior del edificio cuyos restos se han conservado. Existen otros dos pequeños espacios ocupados por un grueso pilar central que pueden ser explicados como cajas de escalera.

\section{Conclusión}

En los momentos anteriores a la llegada de los españoles, Saqsaywaman albergaba un complejo y articulado conjunto de edificios rodeado por terrazas y muros que abrazaban completamente la colina. Algunos de estos estuvieron dedicados a la producción de objetos de prestigio y a su almacenaje. Con todo, destaca la importancia de los espacios que estuvieron asociados a las funciones religiosas polarizadas en torno a cinco rocas que probablemente fueron consideradas manifestaciones sagradas de la naturaleza. Como hemos podido ver, no fueron los únicos espacios religiosos: las construcciones en forma de torre que dominaban la Plaza Ceremonial o la planta baja del Torreón Circular pueden ser propuestas como espacios ceremoniales que conferían a todo el conjunto un aura de prestigio religioso. El laberinto que forman los muros circulares sugiere la existencia de recorridos rituales que, en último extremo, conducían a los tres patios del conjunto (Plaza Ceremonial, Cancha Sur y Plaza Romboidal con el Jardín Sacro) y que debían estar condicionados por orientaciones astronómicas y por las visuales del paisaje natural que suministraban dichos espacios. En este panorama, los espacios litúrgicos y los representativos se integraban en una concepción complementaria que sólo pudo tener como protagonista al propio Sapa 
Inca: Saqsaywaman era «Casa del sol» y, por supuesto, también la casa de su propio hijo.

Garcilaso nos recuerda, además, el uso que se atribuía a estos espacios: «En aquel torreón se aposentaban los Reyes cuando subían a la fortaleza a recrearse, donde todas las paredes estaban adornadas de oro y plata, con animales y aves y plantas contrahechas al natural y encajadas en ellas, que servían de tapicería. Había asimismo mucha vajilla y todo el demás servicio que hemos dicho que tenían las casas reales» (Garcilaso 2004 [1609]: 485-488). Si consideramos estas noticias como algo más que un recuerdo mitificado de la juventud del escritor, deberíamos deducir que el propio Sapa Inca y su «casa real» ocupaban el piso superior del edificio de los torreones. Las pequeñas cámaras y los pasillos que actualmente dibujan los cimientos habrían sostenido una planta principal con las habitaciones nobles y las vistas al paisaje.

Hoy en día Saqsaywaman aparece segregado del espacio urbano del Cusco. Sin embargo, si restituimos las terrazas desaparecidas en la ladera de Qolcampata, se hace evidente que desde Pumachupan, la confluencia de los torrentes que forman el Watanay, hasta la cabeza del Puma en Saqsaywaman, el inca Pachacuti planificó un agregado urbano unitario. En la parte baja de la ciudad estaban las Casas del Sol de Hurin Qusqu. Su corazón sagrado era el recinto del Coricancha, reservado a unos pocos y precedido por la plaza de Intipata, donde se focalizaban las ceremonias colectivas más sagradas. Podemos deducir que su contrapunto dual estaba en Saqsaywaman con las Casas del Sol de Hanan Qusqu. Su Plaza Ceremonial, como el Intipampa, debía ser el espacio litúrgico destinado a las fiestas colectivas que precedía la entrada en el lugar más sagrado: el edificio denominado de los Torreones. Así como el Intipampa estaba provisto de numerosos lugares de culto citados en las listas de los ceques, la Plaza Ceremonial de Saqsaywaman contaba con varios edificios exentos agrupados en una plataforma lateral que pudieron servir para alojar a las huacas y objetos sagrados que subrayaban la gran santidad del lugar. Así, la Plaza Ceremonial en su relación espacial con el Edificio de los Torreones se configura como el principal elemento compositivo de Saqsaywaman: era la antesala del edificio más sagrado, tal como el Inticancha precedía el acceso al Coricancha.

\section{Referencias bibliográficas}

Agurto Calvo, Santiago

1987 Estudios acerca de la construcción, arquitectura y planeamiento incas. Lima: Cámara Peruana de la Construcción.

Alcalé, Luisa Elena

1999 «Imagen e historia: la representación del milagro en la pintura colonial», en Los siglos de oro en los virreinatos de América 1550-1770, pp. 107-126. Madrid: Sociedad Estatal para la Conmemoración de los Centenarios de Felipe II y Carlos V.

2004 «Miraculous Apparition of the Virgin in Cuzco», en The Colonial Andes: Tapestries and Silverwork, 1530-1830, Elena Phipps et al., pp. 150-152. Nueva York: The Metropolitan Museum of Art.

ANGLÉs VARGas, Víctor

1972 Machupijchu: enigmática ciudad inka. Cusco: Industrial Gráfica. 
1990 Sacsayhuaman: portento arquitectónico. Cusco: Industrial Gráfica.

ArKush, Elizabeth

2009 «Pukaras de los collas: guerra y poder regional en la cuenca norte del Titicaca durante el Periodo Intermedio Tardío». Andes 7: 463-479.

Arkush, Elizabeth y Charles STANISH

2005 «Interpreting Conflict in the Ancient Andes». Current Anthropology 46 (1): 3-28.

Aveni, Anthony F.

1981 «Horizon Astronomy in Incaic Cusco», en Archaeoastronomy in the Americas, Ray A. Williamson, ed., pp. 305-318. Los Altos: Ballena Press.

Barreda Murillo, Luis y Abraham Valencia Espinosa

2007 «Introducción a la etnología y arqueología de Saqsaywaman», en Saqsayhuaman: estudios fundamentales, pp. 85-152. Cusco: Instituto Nacional de Cultura.

BAUER, Brian S.

2008 Cusco Antiguo: tierra natal de los Incas [2004]. Cusco: Centro de Estudios Regionales Andinos «Bartolomé de las Casas».

Cieza de León, Pedro

1986 La Crónica del Perú [1553]. Madrid: Sarpe.

1988 El Señorío de los Incas, $3^{\mathrm{a}}$ ed. Madrid: Historia 16.

DAMMERT, Manuel

2007 La red de parques arqueológicos. El apogeo del Tawantinsuyu y el desarrollo regional del Cusco. Cusco: Instituto Nacional de Cultura.

Divale, William T.

1973 Warfare in Primitive Societies: A Bibliography. Santa Barbara: American Bibliographical Center.

Duviols, Pierre

1977 La destrucción de las religiones andinas (conquista y colonia). México: Universidad Nacional Autónoma de México.

ELLEFSEN, Bernardo

1972 Importancia histórica de Incallacta. Cochabamba: Publicaciones de la Corporación de Desarrollo de Cochabamba.

Estete, Miguel de

1924 El descubrimiento y la conquista del Perú [1535]. Colección de Libros y Documentos Referentes a la Historia del Perú, serie 2, tomo 8. Lima: Imprenta y Librería San Martí.

FARRINGTON, Ian

2010 «The Houses and 'Fortress' of Waskar: Archaeological Perspectives on a Forgotten Building Complex in Inka Cusco». Journal of Iberian and Latin American Studies 16 (2): 87-99.

Garcilaso de la VeGa, el Inca

2004 Comentarios reales de los incas [1609]. Lima: A.F.A.

GASPARINI, Graziano y Luise MARGOLIES

1977 Arquitectura inka. Caracas: Universidad Central de Venezuela. 
Guamán Poma de Ayala, Felipe

1980 El primer nueva corónica y buen gobierno [1615], 3 vols. México: Siglo XXI.

Gullberg, Steven R.

2009 The Cosmology of Inca Huacas. Tesis doctoral. Townsville: James Cook University.

Hastorf, Christine A.

1993 Agriculture and the Onset of Political Inequality before the Inka. Cambridge: Cambridge University Press.

Herrera, Alexander

2005 «Las kancha circulares: espacios de interacción social en la sierra norte del Perú». Boletín de Arqueología PUCP 9: 233-255.

IsBELL, William H.

2001 «Huari: crecimiento y desarrollo de un capital imperial», en Wari: arte precolombino peruano, pp. 99-172. Sevilla: Fundación El Monte.

2006 «Landscape of Power: A Network of Palaces in Middle Horizon Peru», en Palaces and Power in the Americas: From Peru to the Northwest Coast, J. J. Christie y P. J. Sarro, eds., pp. 44-98. Austin: University of Texas Press

Kalafatovich, Carlos

1970 «Geología del grupo arqueológico de la Fortaleza de Saccsayhuaman y sus vecindades». Saqsaywaman 3: 44-61.

Kaufmann, H. W. y J. E. Kaufmann

2006 Fortifications of the Incas. Nueva York: Osprey.

Kellner, Corina M.

2001 «Ritual or Just Plain Warfare? Trophy Heads of the Julio C. Tello Collection from Nasca, Peru». American Journal of Physical Anthropology 114 (S32): 89-92.

LAU, George F.

2010 «Fortifications as Warfare Culture: The Hilltop Centre of Yayno (Ancash, Peru), AD 400-800». Cambridge Archaeological Journal 20 (3): 419-448.

LEE, Vincent R.

1986 «The Building of Sacsahuaman». Nawpa Pacha 24: 49-60.

Limón Olvera, Silvia

1990 Las cuevas y el mito de origen: los casos inca y mexica. México: CNCA.

Mazzotti, José Antonio

1996 «The Lightning Bolt Yields to the Rainbow: Indigenous History and Colonial Semiosis in the Royal Commentaries of El Inca Garcilaso de la Vega». Modern Language Quarterly 57 (2): 197-211.

McElroy, Keith

1986 «Ephraim George Squier: Photography and the Illustration of Peruvian Antiquities». History of Photography 10 (2): 99-129.

Meddens, Frank M.

1997 «Function and Meaning of the Ushnu in Late Horizon». Tawantinsuyu 3: 5-14.

Mignolo, Walter D.

2005 «La semiosis colonial: la dialéctica entre representaciones fracturadas y herme- 
néuticas pluritópicas». AdVersuS. Revista de Semiótica 2 (3): 3-28.

MoliniÉ-Fioravanti, Antoinette

1988 «Sanglantes et fertiles frontières: à propos des batailles rituelles andines». Journal de la Société des Américanistes 74: 49-70.

PAREDES, Mónica

2007 «Enterramientos ceremoniales y complejo funerario», en Saqsayhuaman: estudios fundamentales, pp. 233-264. Cusco: Instituto Nacional de Cultura.

Parsons, Jeffrey R., Charles M. Hastings y Ramiro Matos

2000 Prehispanic Settlement Patterns in the Upper Mantaro and Tarma Drainages, Junin, Peru. Volume 2: The Wanka Region. Memoirs of the Museum of Anthropology, 53. Ann Arbor: University of Michigan.

PÉREZ CALDERón, Ismael

1999 Huari: misteriosa ciudad de piedra. Ayacucho: Universidad Nacional de San Cristóbal de Huamanga.

Pino Matos, José Luis

2004 «El ushnu inka y la organización del espacio en los principales tampus de los wamani de la sierra central del Chinchaysuyu». Chungará 36 (2): 303-311.

Protzen, Jean-Pierre

1987-89 «The Fortress of Saqsa Waman: Was it ever Finished?». Ñawpa Pacha 25/27: 155-175.

Proulx, Donald A.

1989 «Nasca Trophy Heads: Victims of Warfare or Ritual Sacrifice?», en Cultures in Conflict: Current Archaeological Perspectives, D. C. Tkaczuk y B. C. Vivian, eds., pp. 73-85. Calgary: University of Calgary.

Ramos GómEz, Luis

2004 «El motivo 'torre' en el escudo de Cuzco y en los queros y otras vasijas andinas de madera de época colonial, del Museo de América (Madrid)». Revista Española de Antropología Americana 34: 163-186.

Rowe, John H.

1944 An Introduction to the Archaeology of Cuzco. Papers of the Peabody Museum of American Archaeology and Ethnology, 27 (2). Cambridge: Harvard University Press.

SAN MARTín M., Juan

2002 «Ritual Conflict (Tinku) and Vindication of Indigenous Rights in Bolivia». Mountain Research and Development 22 (4): 394-396.

Sancho de la Hoz, Pedro

1962 Relación de la conquista del Perú [1534]. Madrid: José Porrúa Turanzas.

Santa Cruz Pachacuti Yamqui Salcamaygua, Juan de

1968 «Relación de antigüedades deste reyno del Perú» [1613], en Crónicas peruanas de interés indigena, F. Esteve Barba, ed., pp. 279-319. Biblioteca de Autores Españoles, 209. Madrid: Atlas.

Saqsaywaman...

2007 Saqsayhuaman: estudios fundamentales. Cusco: Instituto Nacional de Cultura. 
Schenone, Héctor, Andrea JaÚRegui y José E. Burucúa

1994 «Circulación de grabados e imagen religiosa en la cultura barroca de la América, del Sur: un estudio de caso», en Lecturas de historia del arte, IV, pp. 319-325. Vitoria: Instituto Municipal de Estudios Iconográficos Ephialte.

SHERBONDY, Jeanette S.

1987 «Organización hidráulica y poder en el Cuzco de los incas». Revista Española de Antropología Americana 17: 117-153.

SiLLAR, Bill

2002 «Caminando a través del tiempo: geografías sagradas en Cacha/Raqchi, departamento del Cuzco (Perú)». Revista Andina 35: 221-246.

Silva Gonzales, José Carlos

2007 «Saqsaywaman, Casa del Sol de los Incas», en Saqsayhuaman: estudios fundamentales, pp. 153-180. Cusco: Instituto Nacional de Cultura.

SQuier, E. George

1877 Peru: Incidents of Travel and Exploration in the Land of the Incas. Nueva York: Harper and Brothers.

StALlER, John E.

2008 «Dimensions of Place: The Significance of Centers to the Development of Andean Civilization: An exploration of the Ushnu Concept», en Precolumbian Landscapes of Creation and Origin, J. E. Staller ed., pp. 269-313. Nueva York: Springer.

Terada, Kazuo

1979 Excavations at La Pampa in the North Highlands of Peru, 1975. Tokio: University of Tokyo Press.

THORPE, I. J. N.

2003 «Anthropology, Archaeology, and the Origin of Warfare». World Archaeology 35 (1): 145-165.

TopIC, John R. y Theresa L. TOPIC

1987 «The Archaeological Investigation of Andean Militarism: Some Cautionary Observations», en The Origins and Development of the Andean State, J. Haas, S. G. Pozorski y T. G. Pozorski, eds., pp. 47-55. Cambridge: Cambridge University Press.

1997 «Hacia una comprensión conceptual de la guerra andina», en Arqueología, antropología e historia en los Andes: Homenaje a María Rostworowski, pp. 567-90. Lima: Instituto de Estudios Peruanos.

URTON, Gary

1981a At the Crossroads of Earth and Sky: An Andean Cosmology. Austin: University of Texas Press.

1981b «The Use of Native Cosmologies in Archaeoastronomical Studies: The View from South America», en Archaeoastronomy in the Americas, Ray A. Williamson, ed., pp. 285-304. Los Altos: Ballena Press.

1993 «Moieties and Ceremonialism in the Andes: The Ritual Battles of the Carnival Season in Southern Peru», en El mundo ceremonial andino, L. Millones y Y. Onuki, eds., pp. 117-142. Senri Ethnological Studies, 37. Osaka: National Museum of Ethnology.

VALCÁRCEL, Luis Eduardo

2007 «Sajsawaman redescubierto» [1934], en Saqsayhuaman: estudios fundamentales, 
pp. 65-85. Cusco: Instituto Nacional de Cultura.

Valencia Zegarra, Alfredo

1984 «Arqueología de Qolqanpata». Revista del Museo e Instituto de Arqueología 23: 47-62. Cusco.

VAn DE Guchte, Maarten J. D.

1990 'Carving the World': Inca Monumental Sculpture and Landscape. Tesis doctoral inédita. Urbana: University of Illinois.

VENCL, Slavomil

1983 «K problematice fortifikací v archeologii-Fortifications and their Problems in Archaeology». Archeologicke Rozhledy 35: 284-315.

1984 «War and Warfare in Archaeology». Journal of Anthropological Archaeology 3:116-132.

WILSON, David J.

1988 Prehispanic Settlement Patterns in the Lower Santa Valley, Peru: A Regional Perspective on the Origins and Development of Complex North Coast Society. Washington: Smithsonian Institution Press.

Wright, Kenneth R.

2006 Tipon: Water Engineering Masterpiece of the Inca Empire. Reston: American Society of Civil Engineers.

Zecenarro Benavente, Germán

2001 Arquitectura arqueológica en la quebrada de Thanpumach'ay. Cusco: Municipalidad del Cusco.

ZióŁKowsKi, Mariusz S. y Robert M. SADOwSKI

1989 Time and Calendars in the Inca Empire. BAR International Series, 479. Londres.

ZuIDEMA, R. Tom

1981 «Inca Observations of the Solar and Lunar Passages Through Zenith and AntiZenith at Cuzco», en Archaeoastronomy in the Americas, Ray A. Williamson, ed., pp. 319-342. Los Altos: Ballena Press.

1991 «Batallas rituales en el Cuzco colonial», en Cultures et sociétés. Andes et MésoAmérique: Mélanges en hommage à Pierre Duviols, R. Thiercelin, ed., vol. 2, pp. 811-833. Aix-en-Provence: Université de Provence.

2007 «Solar and Lunar Observations in the Inca Calendar», en Skywatching in the Ancient World: New Perspectives in Cultural Astronomy, C. Ruggles y G. Urton, eds., pp. 269-285. Boulder: University Press of Colorado.

2008 «The Astronomical Significance of Ritual Movements in the Calendar of Cuzco», en Precolumbian Landscapes of Creation and Origin, J. E. Staller ed., pp. 249268. Nueva York: Springer. 